\title{
Article
}

\section{Multi-Criteria Decision Making Model for Application Maintenance Offshoring Using Analytic Hierarchy Process}

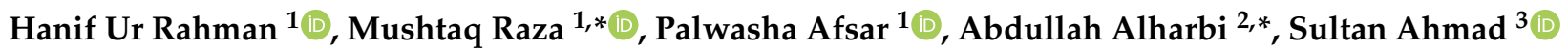 \\ and Hashym Alyami ${ }^{4}$ \\ 1 Department of Computer Science, Abdul Wali Khan University Mardan, Mardan 23200, Pakistan ; \\ hanif.maidan@gmail.com (H.U.R.); palwasha@awkum.edu.pk (P.A.) \\ 2 Department of Information Technology, College of Computers and Information Technology, Taif University, \\ P.O. Box 11099, Taif 21944, Saudi Arabia \\ 3 Department of Computer Science, College of Computer Engineering and Sciences, \\ Prince Sattam Bin Abdulaziz University, P.O. Box 151, Alkharj 11942, Saudi Arabia; s.alisher@psau.edu.sa \\ 4 Department of Computer Science, College of Computers and Information Technology, Taif University, \\ P.O. Box 11099, Taif 21944, Saudi Arabia; hyami@tu.edu.sa \\ * Correspondence: mushtaq@awkum.edu.pk (M.R.); amharbi@tu.edu.sa (A.A.)
}

Citation: Rahman, H.U.; Raza, M.; Afsar, P.; Alharbi, A.; Ahmad, S.; Alyami, H. Multi-Criteria Decision Making Model for Application Maintenance Offshoring Using Analytic Hierarchy Process. Appl. Sci. 2021, 11, 8550. https://doi.org/ 10.3390/app11188550

Academic Editor: Paolino Di Felice

Received: 19 August 2021

Accepted: 8 September 2021

Published: 14 September 2021

Publisher's Note: MDPI stays neutral with regard to jurisdictional claims in published maps and institutional affiliations.

Copyright: (c) 2021 by the authors. Licensee MDPI, Basel, Switzerland. This article is an open access article distributed under the terms and conditions of the Creative Commons Attribution (CC BY) license (https:/ / creativecommons.org/licenses/by/ $4.0 /)$.

\begin{abstract}
The phenomenon of Global Software Development (GSD) has attracted the interest of businesses all over the world. It brings together partners from various national and corporate cultures to develop applications with numerous advantages, including access to a vast labor pool, cost savings, and round the clock growth. GSD, on the other hand, is technologically and organizationally diverse and poses a number of obstacles for the development team, such as geographical distance, cultural differences, communication and language barriers. Global services are provided by selecting one of the suitable global delivery options, i.e., the onshore model, nearshore model or offshore model. Experts typically choose one of the models based on the nature of the project and the needs of the customer. However, the vendors and clients lack an adequate decision support system that can assist them in making suitable sourcing decisions. Therefore, the current study presents a Multi-Criteria Decision Making (MCDM) model for offshore outsourcing decisions of application maintenance. To achieve our target, two systematic literature reviews were conducted that explored a list of 15 influencing factors. The identified factors were further evaluated in the outsourcing industry by performing an empirical study that resulted in a list of 10 critical success factors. We propose a sourcing framework based on the critical success factors that can assist decision makers in adopting a suitable sourcing strategy for the offshore outsourcing of application maintenance. In order to further enhance the decision-making process, the MCDM model is developed based on the Analytic Hierarchy Process (AHP). The MCDM model is evaluated with three case studies in highly reputable international companies, including IBM Stockholm, Sweden, Vattenfall AB, Stockholm, Sweden and a London based company in the United Kingdom. The outcomes of these case studies are further reviewed and validated by the outsourcing specialists in other firms. The proposed model is used as a decision support system that determines the ranking of sourcing alternatives and suggests the most suitable option for application maintenance offshoring.
\end{abstract}

Keywords: application maintenance offshoring; outsourcing; decision support system; multi-criteria decision making model; AHP; global software development

\section{Introduction}

Over the last few decades, Global Software Development (GSD) has been the emerging trend for the development of software across the globe. In the GSD paradigm, software engineering teams are spread across the globe, working together to carry out a project. The organizations have adopted this business strategy in order to obtain quality products at low prices by using the resources of low-wage countries. This brings down the cost 
of software development by utilizing the employees with high skill sets and a wide pool of global resources as well as accessing cheaper resources and global talent. In addition, GSD provides opportunities, such as the development of software by following the sun, software development round the clock, access to qualified developers and engineers, access to online available resources, and obtaining economic as well as business growth [1-3].

Organizations are always looking for new business strategies to gain competitive advantages. By adopting outsourcing, the organizations gain competitiveness. Outsourcing is a strategy that engages an external vendor in order to receive services, such as software development, maintenance, data entry operations, facility management and telecommunication services. Software development outsourcing is a business strategy that has been adopted by organizations for the last two decades. This can be defined as "an agreement between client and vendor where the client hands over its software or part of it to vendor and vendor provides the services". In other words, software development outsourcing is a mechanism involving a third party to provide maintenance services either using an onshore model or an offshore model. Similarly, outsourcing strategies are increasingly used by firms in the leading countries; namely the US, UK and Japan. These firms outsource their projects to low-wage countries, like China, India, South Korea, Russia and Ireland, to find cost efficient solutions. Offshore outsourcing or offshoring or global outsourcing is defined as the engagement of geographically distant vendors to provide services at a low cost across national borders. The major reason for adopting this strategy is the reduction of software development cost. Organizations cut down development costs about $30-50 \%$ by using the offshore outsourcing strategy [1-7].

According to Lacity et al. [8], the market size of Information Technology (IT) outsourcing and Business Process (BP) outsourcing was 373 US billion dollars in 2011 and 424 US dollars in 2014 with 4.4\% annual growth. Similarly, "Horses for Sources" estimated the market growth of IT outsourcing and BP outsourcing for 2013 as double, i.e., 952 billion dollar [8]. Likewise, it is expected that the market size of IT outsourcing alone would be 64.3 billion dollars between 2018 and 2021, with 2.4\% of annual growth. A number of business functions are outsourced, such as IT, financial services, management of human resources, logistics and manufacturing [9].

IT outsourcing has sub categories; namely software development, software maintenance, infrastructure and business process [1]. Software maintenance is an important part of the development phase. Software maintenance modifies an existing application in order to correct errors, deal with new technology and platform, and adapt to a new environment. According to the IEEE standard [10] software maintenance is defined as "the modification of software after its delivery to fix errors, to increase the performance and to adapt the application to a changing environment". After becoming operational, the software system enters into the maintenance phase. Maintenance is aimed at keeping the software operational according to the needs of clients. The main categories of software maintenance are corrective, perfective, adaptive and preventive. Software maintenance is the most costly and the time consuming phase of software development life cycle. A significant portion of the total budget of information technology is consumed only by application maintenance activity, i.e., approximately $60-70 \%$ of the total software life cycle cost is spent alone on maintenance [10,11].

Therefore, organizations adopt the offshoring strategy in order to significantly reduce their maintenance costs by utilizing the cheaper resources of low-wage countries. The global delivery models combine regional, local and global expertise to provide maintenance services at low cost. Companies, like IBM and Accenture, have strong global delivery capabilities that provide application maintenance services from offshore, nearshore and onshore locations by using offshore, nearshore and onshore models [12].

\section{Research Gap and Motivation}

In order to provide application maintenance in the offshore outsourcing context, the IT experts and decision makers select one of the three models, which are onshore, nearshore 
and offshore. Experts typically choose the model based on the nature of the project and the needs of the customer. However, the vendors and clients lack an adequate decision support system that can assist them in making suitable sourcing decisions. Similarly, experts lack a decision support mechanism that allows them to rank the available alternatives for the offshore outsourcing decision of application maintenance.

As a result, the current study presents a multi-criteria decision support system that assists IT experts and practitioners in selecting the most suitable and appropriate sourcing alternative. Thus, the appropriate model selection would result in a successful offshore outsourcing decision. Furthermore, the following goals inspired us to conduct this research:

- Due to the involvement of multiple factors and sub factors the multi-criteria decision making is a big challenge in application maintenance offshore outsourcing;

- Application maintenance offshoring has been a hot research topic for the academicians and scholars since the last two decades, which motivated us to develop a multi-criteria decision support system;

- Another reason for the present research is that there is a gap between the literature and the proposed work. Using systematic literature reviews, we first identified a list of influencing factors. The factors have already been established and reported in the previous studies [2,3]. Second, we performed an empirical study [1] in the outsourcing industry that evaluated the identified influencing factors. Third, a multicriteria decision making model, based on the identified critical success factors is proposed for the sourcing decision of application maintenance in the current paper. To the best of our knowledge, no such approach has ever been used to identify the critical success factors of application maintenance offshoring and to tackle the challenges in making the sourcing decisions.

The rest of the paper is organized as follows: Section 2 presents the research background, which includes a detailed discussion of MCDM problems and proposed models in GSD and other domains, Section 3 shows the proposed research methodology that consists of a systematic literature review, empirical study and AHP technique for the proposed MCDM model. Similarly, Sections 4 and 5 presents our results and conclusions, respectively.

\section{Study Background}

The GSD phenomenon has attracted the interest of businesses all over the world. It brings together partners from various national and corporate cultures to develop applications with numerous advantages including access to a vast labor pool, cost savings and round the clock growth. GSD, on the other hand, is technologically and organizationally diverse and poses a number of obstacles for the development team, such as geographical distance, cultural differences and communication and language barriers [13]. Vendors provide services to clients by selecting one of the suitable global delivery options. The selection of an appropriate model is a Multi-Criteria Decision Making (MCDM) problem. The literature review shows that prior studies addressed the complex problem of MCDM by using various tools, such as Analytic Hierarchy Process (AHP), Analytic Network Process (ANP), Fuzzy TOPSIS, Fuzzy AHP and Fuzzy Set Theory. Karami and Guo [14] developed a multi-criteria system based on 10 risk factors using Fuzzy logic. The proposed MCDM framework is used to handle the uncertainty involved in the selection process of vendors. Huang and Sun [15] presented a novel AHP-based risk assessment model using three factors, including confidentiality, availability and integrity and six sub factors for the industrial Internet of Things (IOT) cloud for the purpose of checking the health.

Chandani and Gupta [16] presented a novel method based on AHP for the prioritization of requirements risks in order to identify the most critical requirement. The basic idea is the identification of critical requirements and to communicate it with team members and stakeholders. This method helps the developers and all stakeholders to know about the requirements' risks, which minimizes the rate of project failure.

Similarly, the literature review showed that a number of articles presented Decision Support Systems for software, such as Moaven et al. [17], which proposed a De- 
cision Support System (DSS) for the software architecture selection based on the fuzzy logic. It provides architects the suitable choices among the available architecture styles. Büyüközkan et al. [18] designed a multi-criteria decision system based on two main factors, namely economic and quality, and a number of sub factors using AHP. This was used for the selection of effective software development strategies to meet the requirements of the clients, cut down the cost and enable the company to compete in the market.

Silva et al. [19] introduced a multi-criteria method based on SMARTER for assisting the experts in selection of the best-fit agile product development methodology for small and medium size companies. Agrawal et al. [20] integrated Fuzzy TOPSIS and Fuzzy AHP to evaluate the sustainable security of web applications. They used four main attributes, which are confidentiality, availability, integrity and perdurability, along with other sub factors. The technique was tested, and it can help researchers and developers in designing the higher sustainable and secure web applications.

Tanoumand et al. [21] used Fuzzy AHP to select the most suitable service provider for the cloud services. The criteria used in this technique are the availability, CPU, transaction cost, security, storage and performance. Moaven and Habibi [22] adopted the Fuzzy AHP technique for the selection of software architecture style. The proposed technique helps the architects in the evaluation of the candidate architectures based on the criteria, namely portability, efficiency, reliability, maintainability, usability and functionality; and other sub factors. The most useful architectural style is chosen based on the stakeholders' requirements and viewpoints.

Sayed et al. [23] proposed an AHP-based technique to select a suitable agile method according to the project need and nature. The criteria that were used were dynamic requirements, requirement changes, development team and communication. Similarly, Ali et al. [24] presented a multi-criteria decision making model based on Fuzzy logic for cloud adoption. The criteria and sub criteria of software testing that were used in making the multi-criteria model were identified by performing a systematic literature review and empirical study. The proposed model was used by the decision makers to suggest cloud adoption for software testing.

Wang et al. [25] proposed a framework based on AHP and TOPSIS that evaluates the security of IOT devices. The proposed framework consists of two phases; First, weights of the factors are calculated by using AHP. Second, the alternatives are assessed with respect to criteria by using the TOPSIS technique. The proposed framework suggests the most secure and reliable option among the available alternatives. Li et al. [26] proposed a decision support system based on ANP for the selection of requirements elicitation techniques. A total of 14 factors were identified through the literature; namely key stakeholders, computer literacy, schedule constraints, stakeholders' diversity, organization culture, prospective system's nature, number of people in a session, expressiveness of users, reusable requirements, financial constraints, stakeholders' relationship, domain knowledge, existing system maintenance, relationship of clients and analysts. The model is based on these requirements elicitation's attributes that suggests one of the suitable techniques from the six alternatives.

Alzahrani [27] proposed a novel technique to asses the usability and security of healthcare software by using the combination of three tools, Fuzzy logic, ANP and TOPSIS. It is the most effective technique that assesses the usable security of applications regarding healthcare. The results produced by the proposed model can be used in the management of security with no impact on users usability.

Akbar et al. [28] conducted a systematic literature review and then performed industrial survey to validate the results. They identified a total of 30 best practices regarding cloud based global software development. These practices were categorized into eight groups, including resource management, integration, communication, stakeholders, procurement, time, scope and quality. The best practices of cloud were prioritized by using Fuzzy AHP technique.

Ikram et al. [29] performed an empirical study that identified a data set that comprised of 19 attributes, namely supplier size, team size, domain, project size, following interna- 
tional standards, code complexity, following standard in documentation, quality of document, maintenance type required, code structure, time zone, client's experience, language barrier, Service Level Agreement (SLA), method adopted and age of the system. A machine learning technique was proposed based on the identified attributes for service providers to assess the client proposal in offshore software maintenance outsourcing scenarios.

Akbar et al. [30] explored the development and operational challenges by using Systematic Literature Review (SLR), which was followed by an online survey to validate the identified list of factors. The research study resulted in a list of critical success factors that are faced by companies while using the development and operations (DevOps). The identified critical challenges were prioritized using the Fuzzy AHP technique.

Riskiana et al. [31] discussed that, due to software failures, when the stakeholders are unable to meet the SLA, this leads to the dissatisfaction of the client and impacts the vendor performance as well. They examined the factors that cause the software failures and adopted the AHP technique to prioritize these factors. Nazir et al. [32] used these attributes, such as access control, authentication, non-repudiation, confidentiality of data, communication flow, integrity of data, availability and privacy. On the basis of these attributes, they presented a Fuzzy logic model that helps the software engineers to select software components.

Wang et al. [33] selected five factors from the literature: strategy, economics, risk, quality and environment. They proposed a multi-criteria model based on these factors by using AHP and ELECTRE III. The AHP technique provides the weights of the criteria, whereas the ELECTRE III calculates the final rankings.

In the context of intuitionist two tuple linguistic information, Faizi et al. [34] suggested two techniques for best-worst methods, namely the linear best-worst method and the Euclidean best-worst method, to produce the best criteria priority vector for Multi-Criteria Group Decision Making (MCGDM) situations. Similarly, Baczkiewicz et al. [35] presented a DSS based on multi-criteria decision analysis (MCDA) techniques for sustainable evaluation. The capabilities of the system were demonstrated through the use of renewable energy sources in European countries.

Shekhovtsov et al. [36] solved a numerical example by six different MCDA techniques that resulted in a complete ranking. Rehman et al. [37] devised a system based on the AHP framework's criteria, with a decision matrix that was built by utilizing consistent fuzzy preference relations. The symmetrical decision matrix technique was used. The suggested methodology's rationale and effectiveness were demonstrated through a range of numerical explanations and an analysis of quantitative findings. A summary of the related work is given in the following Table 1.

Table 1. Summary of the study background.

\begin{tabular}{|c|c|c|}
\hline Techniques & Source & Description \\
\hline Fuzzy logic [14] & Empirical study & $\begin{array}{c}\text { Breach of contract, lack of expertise and experience, cultural difference, no } \\
\text { project management experience, costly amendments in contract, disputes and } \\
\text { litigation, financial stability of providers, security breach, contract is not } \\
\text { flexible and lack of innovation. }\end{array}$ \\
\hline AHP [15] & Literature & Confidentiality, availability, integrity and six sub factors. \\
\hline AHP [16] & Literature review & Impact, perspective, frequency, dependency, type and sub factors. \\
\hline Fuzzy Int [17] & Literature & Performance, functionality, maintenance. \\
\hline AHP [18] & Literature, interviews & Software economic, software quality and sub factors. \\
\hline SMARTER [19] & Literature review & Project setup, project management, project complexity and sub factors. \\
\hline AHP, TOPSIS [20] & Empirical study & Confidentiality, perdurability, integrity, availability and other sub factors. \\
\hline Fuzzy AHP [21] & Literature, experts & Availability, CPU, transaction cost, security, storage and performance. \\
\hline Fuzzy AHP [22] & Literature & $\begin{array}{l}\text { Portability, efficiency, reliability, maintainability, functionality, usability and } \\
\text { sub factors. }\end{array}$ \\
\hline
\end{tabular}


Table 1. Cont

\begin{tabular}{|c|c|c|}
\hline Techniques & Source & Description \\
\hline AHP [23] & Literature & $\begin{array}{c}\text { Dynamic requirements, requirement changes, development team and } \\
\text { communication. }\end{array}$ \\
\hline Fuzzy Set Theory [24] & SLR, empirical study & $\begin{array}{l}\text { Economic benefits, efforts expectancy, competency, external stimuli, planning } \\
\text { of feasibility and analysis of risk, performance expectancy, utilization of } \\
\text { resources, trust, organization dynamics, business concerns and sub factors. }\end{array}$ \\
\hline AHP and TOPSIS [25] & Literature & $\begin{array}{l}\text { Confidentiality, availability, security, trustworthiness, authentication, } \\
\text { authorization, key management, integrity, access control, non-repudiation, } \\
\text { network monitoring, auditing and continuity. }\end{array}$ \\
\hline ANP [26] & Literature & $\begin{array}{l}\text { Key stakeholders, computer literacy, schedule constraints, stakeholders' } \\
\text { diversity, organization culture, prospective system's nature, number of } \\
\text { people/session, expressiveness of users, reusable requirements, financial } \\
\text { constraints, stakeholders' relationships, domain knowledge, existing system } \\
\text { maintenance, relationship of clients and analysts. }\end{array}$ \\
\hline $\begin{array}{l}\text { Fuzzy set, AHP and } \\
\text { TOPSIS [27] }\end{array}$ & Literature & Confidentiality, integrity, availability, identification and other sub factors. \\
\hline Fuzzy AHP [28] & SLR, empirical study & $\begin{array}{l}\text { Resource management, integration, communication, stakeholders, } \\
\text { procurement, time, scope, quality and other sub factors. }\end{array}$ \\
\hline Machine learning [29] & Empirical study & $\begin{array}{l}\text { Supplier size, team size, domain, project size, following international } \\
\text { standards and documentation, code complexity, quality of document, } \\
\text { maintenance type required, code's structure, time zone, client's experience, } \\
\text { language barrier, SLA, method adopted and age of system. }\end{array}$ \\
\hline Fuzzy AHP [30] & SLR, empirical study & Measurement, culture, automation, sharing and 20 sub factors. \\
\hline AHP [31] & Literature & $\begin{array}{c}\text { Software error, operator error, hardware as well as environmental error, error } \\
\text { of fault recovery, issues in change management, issues in communication } \\
\text { management, institutional pressure and violation of security. }\end{array}$ \\
\hline FST [32] & Literature & $\begin{array}{l}\text { Access control, authentication, non-repudiation, confidentiality of data, } \\
\text { communication flow, integrity of data, availability and privacy. }\end{array}$ \\
\hline AHP and ELT [33] & Literature & Strategy, economics, risk, quality and environment. \\
\hline Proposed work & $\begin{array}{c}\text { AHP, SLR, empirical } \\
\text { study }\end{array}$ & $\begin{array}{c}\text { Employee skills, cost, legal requirements, poor communication, infrastructure, } \\
\text { language barrier, maturity level, frequent changes in requirements, domain } \\
\text { knowledge and project management. }\end{array}$ \\
\hline
\end{tabular}

\section{Proposed Method}

The current study aims to introduce a Multi-Criteria Decision Making (MCDM) model by using the AHP technique for offshore outsourcing decisions of application maintenance. To achieve our target, the existing literature was thoroughly analyzed by performing two systematic literature reviews that identified influencing factors of application maintenance offshoring. The conducted systematic literature reviews are cited as $[2,3]$ that give a list of influencing factors regarding offshoring the application maintenance.

The influencing factors were further evaluated in the outsourcing industry by performing an empirical study [1] that ranked 10 factors as critical success factors. In the current study, a MCDM model is developed based on the influencing factors identified in [2,3], and which were further validated and reported in [1]. Literature review showed that previous studies $[5,24,28,30,38,39]$ also adopted the same method. The three phases of the proposed research method, as shown in Figure 1, are discussed in the following subsections. 


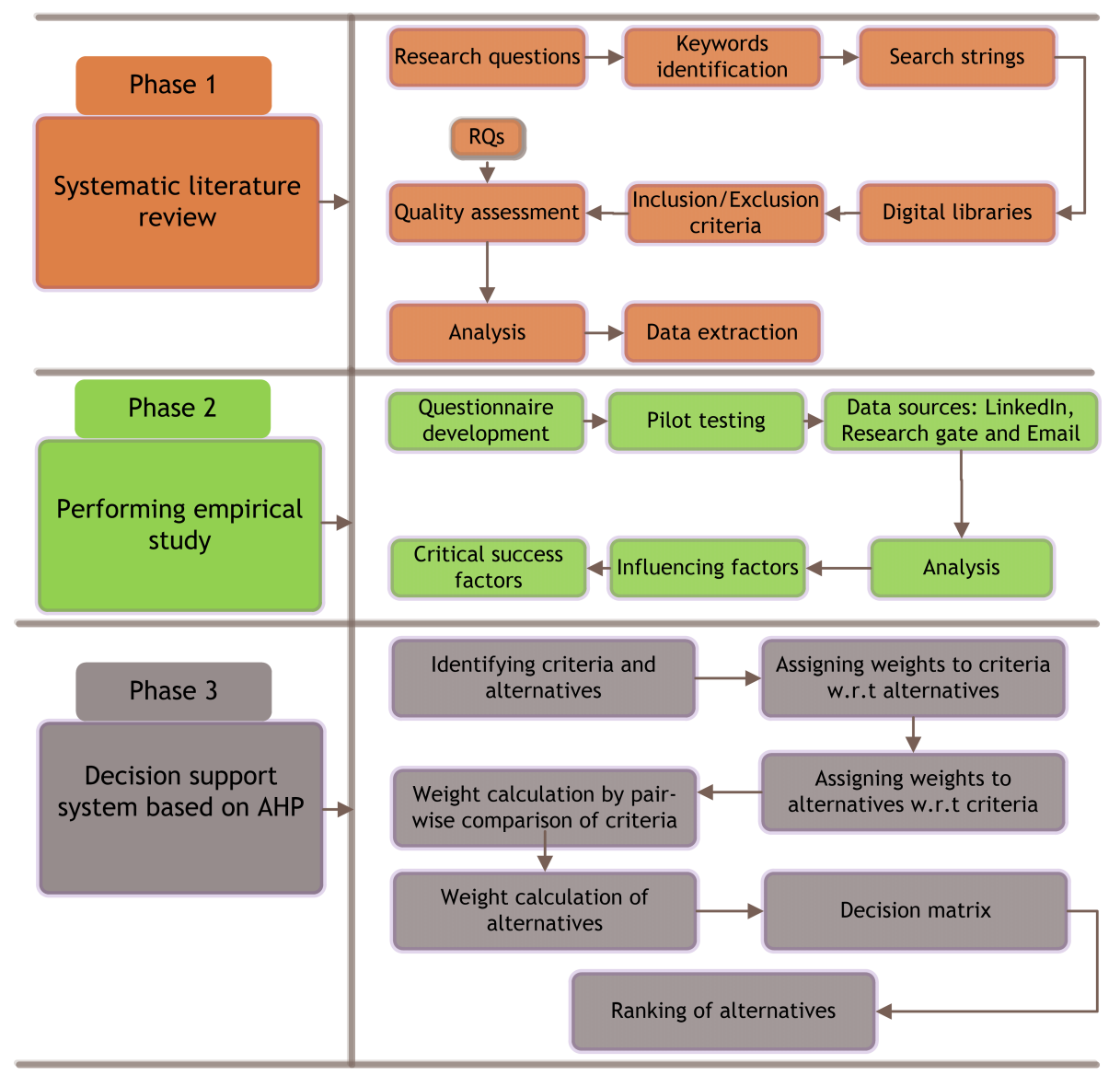

Figure 1. The proposed method of research.

\subsection{Performing Systematic Literature Review}

A systematic literature review is a well-known method for systematically examining and evaluating a research topic. The selected published work is screened, assessed and analyzed against the specified questions using this method. A systematic literature review varies from a literature review, as it follows a predetermined study review procedure. In comparison to a traditional literature review, the results obtained through a systematic literature review are considered less biased, more reliable and more accurate. A systematic literature review is divided into three phases, which are organizing the review, performing the review and reporting the review $[40,41]$.

Figure 1, shows that the first phase of our research consisted of a systematic literature review. We performed two systematic literature reviews as cited [2,3] by following Kitchenham's recommendations [40]. The systematic literature review was adopted for the identification of influencing factors, whereas the same method was used by previous studies [42-44]. The main steps that were followed to conduct the systematic literature review were defining the study questions, identifying and combining keywords, the development of strings, setting inclusion/exclusion criteria, quality evaluation, data synthesis and analysis of the results. The detailed discussion of all these steps along with the identified factors were reported in $[2,3]$.

\subsection{Performing Empirical Study}

As, indicated by Figure 1, empirical study was the second phase of the proposed research method. In order to validate the findings of the systematic literature review, an empirical study (online survey) was performed as cited [1] that ranked 10 factors out of 15 as critical success factors. By using the online survey (questionnaire), the identified factors were evaluated by 93 outsourcing experts across the 30 countries. Previous research studies [45-47] employed a similar strategy for factor assessment and evaluation. 
A total of 93 responses were collected through an online "Google Form" during April 2020 to August 2020. The outsourcing experts were identified by using LinkedIn, Research gate and Google scholar. The experience levels of the respondents as well as their positions are shown in Figure 2. The complete list of responses, demographics of respondents and analysis of factors based on variables, such as experts positions, experts continents and experts experience levels; statistical analysis of data, such as Chi square test (linear by linear association) and performing Correlation Rank Analyses, were performed and reported in [1].

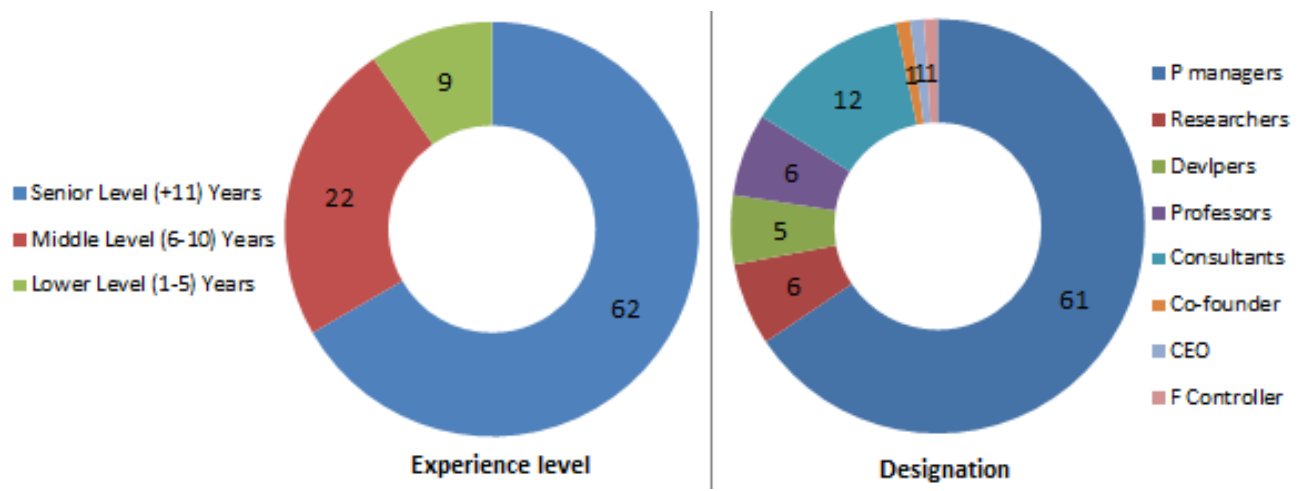

Figure 2. Designations of respondents and their experience levels.

\subsection{AHP Technique for MCDM Problem}

The final and third phase of our proposed research method was the development of an MCDM model based on the AHP technique. By considering multiple criteria for taking a decision, this type of decision making is called MCDM. The primary purpose of MCDM is to rank the alternatives and, consequently, to select the most appropriate alternative by applying certain techniques along with considering specific criteria. MCDM has a variety of applications in different fields, such as engineering, management and economics. MCDM is divided mainly into two classes, which are Multi-Attribute Decision Making (MADM) and Multi Objective Decision Making (MODM).

MADM consists of discrete factors as well as a limited number of alternatives, whereas MODM has continuous variables as well as alternatives, which are unlimited. In the literature, the terms MADM and MCDM are used interchangeably. Over the past years, several MCDM techniques have been proposed by researchers, namely TOPSIS, GDM (Gray Decision Making), ELECTRE (Elimination and Choice Expression Reality), SWARA (Step Wise Weight Assessment Ratio Analysis), AHP and ANP (Analytic Network Process) [48,49].

Aires and Ferreira [50] discussed that, despite the extensive use of MCDM methodologies, the primary approaches, such as AHP, TOPSIS, ELECTRE, PROMETHEE, and their combinations have been criticized because of an issue known as the rank reversal problem. Rank reversal is defined as when a new option is introduced to a set or one of the existing alternative is deleted, the order of the alternatives in that set changes.

Kizielewicz [51] introduced the merging of the TOPSIS and PROMETHEE II methods with the characteristic objects method, which is resistant to the rank reversal problem. The characteristic objects method needs a massive number of pair comparisons, which grows exponentially in proportion to the number of criteria applied.

AHP is one of the most important methods of MCDM and was developed by Thomas Saaty in the 1970s. This is an accurate and precise method for the variables ranking and their prioritization. Similarly, it is a flexible decision making technique that can be used easily. AHP uses a hierarchical structure to present a complex problem and make it simple by splitting it into sub problems. One of the most important features of AHP is that it organizes both the intangible and tangible variables in a systematic manner and offers a structured and comparatively simple solution to the multi-criteria decision making problems.

This approach is well suited to fields where intuition, logic and irrationality are present in relation to risk and uncertainty. The problem may include significant social, political, 
economic and technical amounts, as well as a variety of goals, criteria and alternatives. This method is used for assigning weights/scores to criteria and alternatives. In the current study, weights were assigned to influencing factors and the sourcing alternatives. For the purpose of pairwise comparison, the scale used to provide preferences to criteria as well as alternatives is given in Table 2 [52-54].

The current study aimed to compute the relative priorities/weights of influencing factors as well as to rank the available alternatives. Therefore, the classical AHP was the most suitable technique to calculate weights of the influencing factors and to rank the available sourcing models. Further, AHP has been used by other researchers in the same domain to solve the multi-criteria decision making problems, such as [55-57].

Table 2. The proposed scale by Saaty.

\begin{tabular}{ccc}
\hline Score & Meaning & Explanation \\
\hline 1 & Equal & Two factors are equally important \\
2 & Weak important & Weakly important from the other \\
3 & Moderate important & One factor is slightly preferred over other \\
4 & Moderate plus & Moderate important from the other \\
5 & Strong important & One factors is strongly preferred over the other \\
6 & Strong plus & One factor is more stronger than the other \\
7 & Very strong & One factor is very strongly preferred over the other \\
8 & Very, very strong & Very very stronger than the other \\
9 & Absolute important & One factor is absolutely more important than the other \\
\hline
\end{tabular}

The selection of an effective and most appropriate model for the offshore outsourcing decision of application maintenance depends on various criteria, which were derived by using SLR and validated by performing empirical study, namely the employee skills, cost, poor communication, legal requirements, infrastructure, maturity level, frequent requirement changes, domain knowledge, language barrier and project management. Since the selection of the best model is based on multiple variables and the decision makers need to adopt one of the three available alternatives, it is a MCDM problem. For solving this problem, we adopted the AHP technique to select suitable alternatives among the available options.

\section{Results and Discussion}

This segment presents the findings and discussion of the current study, which are as follows: Section 4.1 presents a list of 15 influencing factors by using systematic literature review, a list of 10 critical success factors by performing empirical study and the proposed sourcing framework. Similarly, Section 4.2 presents an MCDM model based on the AHP technique.

\subsection{Influencing Factors, Critical Success Factors and the Proposed Sourcing Framework}

We conducted systematic literature reviews that presented a list of 15 influencing factors for the sourcing decisions. The influencing factors regarding the application maintenance offshoring were previously published and reported in $[2,3]$. Table 3 , contains the list of influencing factors identified by using systematic literature reviews. However, the detailed discussion of the factors and their identification process is provided in $[2,3]$. 
Table 3. Identified factors through the systematic literature review.

\begin{tabular}{cccc}
\hline S.No & Influencing Factors & Frequency & Percentage \\
\hline 01 & Cost & 27 & 69 \\
02 & Legal requirements & 27 & 69 \\
03 & Language barrier & 23 & 59 \\
04 & Maturity level & 24 & 61 \\
05 & Frequent requirement changes & 24 & 61 \\
06 & Service scope & 5 & 13 \\
07 & Cultural diversity & 19 & 49 \\
08 & Time zone difference & 16 & 41 \\
09 & Knowledge transfer & 22 & 56 \\
10 & Project management & 22 & 56 \\
11 & Domain knowledge & 12 & 31 \\
12 & Employee skills & 30 & 77 \\
13 & Infrastructure & 24 & 61 \\
14 & Poor communication & 27 & 69 \\
15 & Size of engagement & 5 & 13 \\
\hline
\end{tabular}

The findings of the systematic literature review were validated by 93 experts using an empirical study in the outsourcing industry across 30 countries [1]. The identified influencing factors were analyzed on the basis of their respective frequencies and by using statistical analysis, such as the Chi square test (Linear by Linear association) and Spearman Rank Correlation Analysis. As a result, 10 influencing factors were ranked as critical success factors as given in Figure 3 [1].

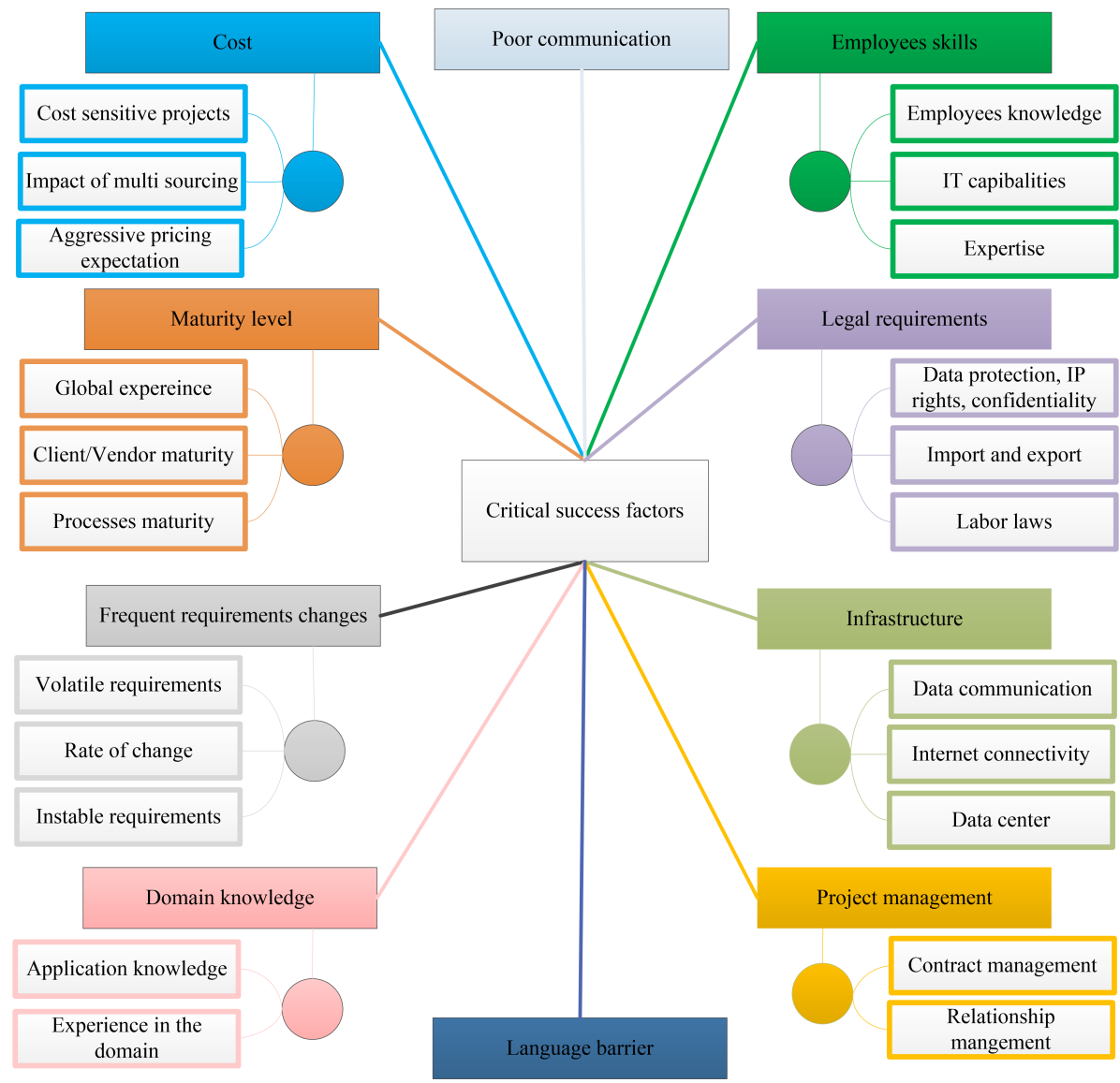

Figure 3. List of the identified critical success factors.

A sourcing framework is proposed based on the identified critical success factors for the sourcing decisions of application maintenance. The suggested framework is shown 
in Figure 4, and may be used by clients as well as on the vendor side to assess a project's nature and requirements. Consequently, upon the evaluation of a project, an appropriate sourcing model is selected among the available alternatives. The alternatives are the onshore model, nearshore model and offshore model. The proposed framework is based on the factors; namely employee skills, cost, poor communication, legal requirements, maturity level, infrastructure, frequent requirement changes, domain knowledge, language barrier and project management. In the following paragraphs, the decision making through the proposed model is shown.

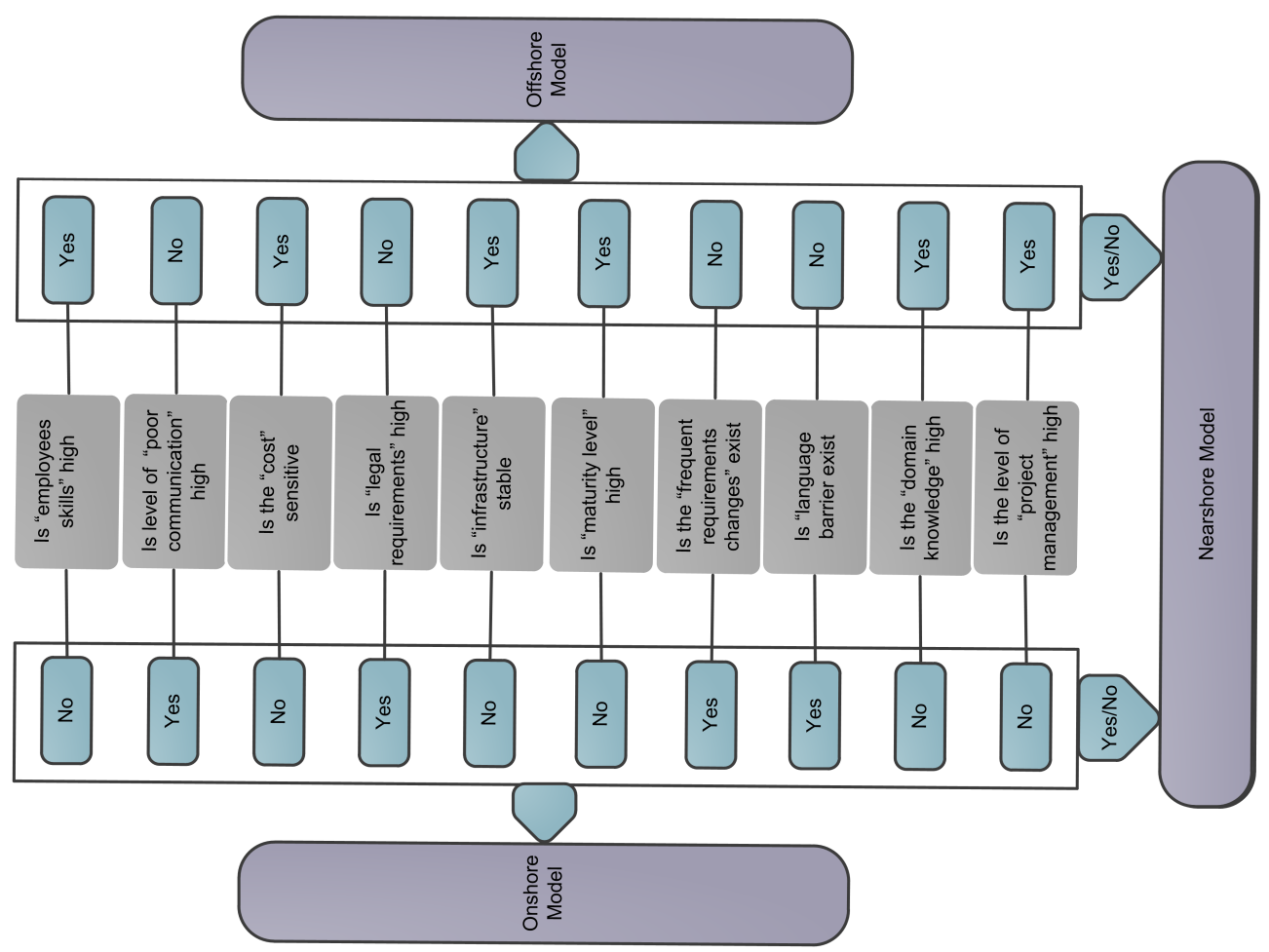

Figure 4. Sourcing framework of application maintenance offshoring.

The sub factors of "employee skills" are the employee knowledge, qualifications, skills and IT capabilities. Vendors with a diverse skill sets and experience are ideally positioned to deliver quality software and services to their consumers. Similarly, a client's employees with business knowledge and IT capabilities enable the company to successfully obtain the services from vendors. Prior to making an outsourcing decision, the customer typically assesses the service provider's capabilities in terms of skills and experience [44,58-60].

Poor communication can result in a breakdown of coordination, delays, stakeholder tensions, project visibility issues and requirement elicitation issues. Communication between the members of distributed teams is hindered by the main challenges of global sourcing, such as cultural diversity, language barrier and time zone differences. Many questions are not answered due to a lack of coordination or inadequate communication, and programmers on other platforms make incorrect assumptions. In some cases, changes are not reported to other departments in a timely way, which causes difficulties in providing services in the global delivery. Therefore, in GSD, inadequate coordination and communication leads to a high amount of vulnerabilities and inefficiency [3,61-63]. As a consequence, poor communication (Yes) shows the suitability of the onshore model.

The vendor's transaction and development costs go up when local workers are involved. Therefore, organizations in high-cost countries, such as the United States, Japan, the United Kingdom and Australia outsource application maintenance, while companies in low-cost countries, such as China, Ireland, India and Russia, deliver services. Offshoring strategy is used by businesses to save the cost of application maintenance around $20 \%$ to 
$50 \%$. Thus, software maintenance at low cost (Yes) motivates both the client and vendor for offshore outsourcing decisions [2-4,64-67].

The sub factors of legal requirements are the protection of intellectual property, confidentiality, data protection, restrictions of imports/exports, currency exchange, labor laws, data transfer restrictions, taxes and government approval regarding offshoring. Since no international rules exist that adequately cover an individual's work abroad, IP rights protection is a challenge to global sourcing. Some countries, such as the United States and Europe, have labor and work policies that hinder the outsourcing process for both the consumer and the provider $[3,68,69]$. Therefore, the onshore model is preferred in case legal requirements exist (Yes). However, services may be delivered using an offshore model if the legalities of a project are resolved or if the project does not have strict legal criteria (No).

Data networking, internet connectivity, network, data centers and servers are the sub factors of infrastructure. Appropriate infrastructure (Yes) motivates the global sourcing decisions. On the other hand, a lack of stable infrastructure (No) would have a negative impact on global delivery and suit the onshore model $[2,68,69]$.

Prior global expertise, customer and provider experience and process maturity are the sub factors that make up the factor "maturity level". If the provider or client lacks the necessary skills (No), such as global expertise and previous experience, the outsourced project may fail. Hence, for this type of project, the nearshore model is chosen. The maturity of the customer and vendor (Yes), on the other hand, favors the offshore model $[2,70,71]$.

"Frequent requirement changes" includes volatile requirements, the instability of requirements, unclear requirements and changes in the application portfolio. Certain projects fail due to ambiguous and unspecified requirements (Yes) along with other global constraints. Requirement uncertainty means a company does not have a clear idea of what it needs from a specific business process. In these situations, the onshore model is preferable over the offshore model. While using the offshore model, changes in requirements can be managed by hiring onsite employees $[1,39,72-74]$.

While dealing with offshore team members with heavy accents, such as Indians, Russians and Chinese, the language challenge is compounded when using landlines. To provide help desk services on a remote site, provider employees should be native speakers or they should be able to speak the client's language fluently to avoid communication gaps. Language differences (Yes) may cause problems during the requirements gathering process of outsourced projects, and the requirements gathered may not accurately represent the needs of the customers [7,75-77]. Currently, the language barrier is handled, and services are provided by using an offshore model.

Similarly, the factors "domain knowledge" and "project management" have an impact on offshore outsourcing decisions. The management of distributed teams across multiple countries is a difficult task $[61,62,78]$. Therefore, the vendors with high management capabilities and domain knowledge (Yes) prefer offshore models. On the other hand, the onshore model fits the minimal domain awareness as well as project management.

Similarly, a nearshore model is adopted to provide services based on the nature of the project, customer demand, and to manage restrictions, such as language constraints (Yes) and strong legal requirements (Yes).

\subsection{Multi-Criteria Decision Making Model Based on AHP}

The suggested sourcing framework as shown in Figure 4, and the project assessment model presented in our previous article [1] are both used to evaluate a project based on the critical success factors that contribute to an effective sourcing decision. However, applying the suggested sourcing framework and project assessment model to evaluate a project prior to making a sourcing decision requires sufficient domain expertise, and the decision making is time consuming as well.

Second, all the sourcing decisions of application maintenance cannot be made on the basis of "Yes" or "No" as shown in Figure 4, and "Low", "Medium" or "High" as 
published and reported in [1]. Therefore, an effective MCDM approach is needed to assist the practitioners in prioritizing the sourcing alternatives and making the best possible sourcing decision. To achieve this goal, the current study presents a decision support system based on AHP that incorporates the input of experts and ranks the sourcing alternatives.

The main steps of the AHP approach for developing decision support system are defining objectives, identifying criteria and alternatives, a pairwise comparison of criteria, assigning a score to alternatives with respect to each criteria, calculating the weights of criteria and alternatives and identifying the final ranking of alternatives by combining the weights of criteria and alternatives [79-81]. The following subsections discuss each of these steps in detail.

\subsubsection{Criteria, Alternatives and Hierarchical Structure}

Our previous studies [1-3] identified a list of 15 influencing factors, which were further validated in the outsourcing industry, that resulted in a list of 10 critical success factors regarding the offshore outsourcing decision of application maintenance. These factors were Employees Skills (ES), Poor Communication (PC), Cost (Cos), Legal Requirements (LR), Infrastructure (Inf), Maturity Level (ML), Frequent Requirements Changes (FRC), Language Barrier (LB), Domain Knowledge (DK) and Project Management (PM).

Similarly, the alternatives, which were adopted to provide global services, are the Onshore Model (OM), Nearshore Model (NM) and Offshore Model (OfM). The hierarchical structure represents the goals, criteria and alternatives as shown in Figure 5. The highest level of the hierarchical structure represents the goal, which is the sourcing decision of application maintenance. The second level of hierarchy shows criteria that consists of an identified list of critical success factors, whereas the third level consists of alternatives showing the available models for providing global services [56,80].

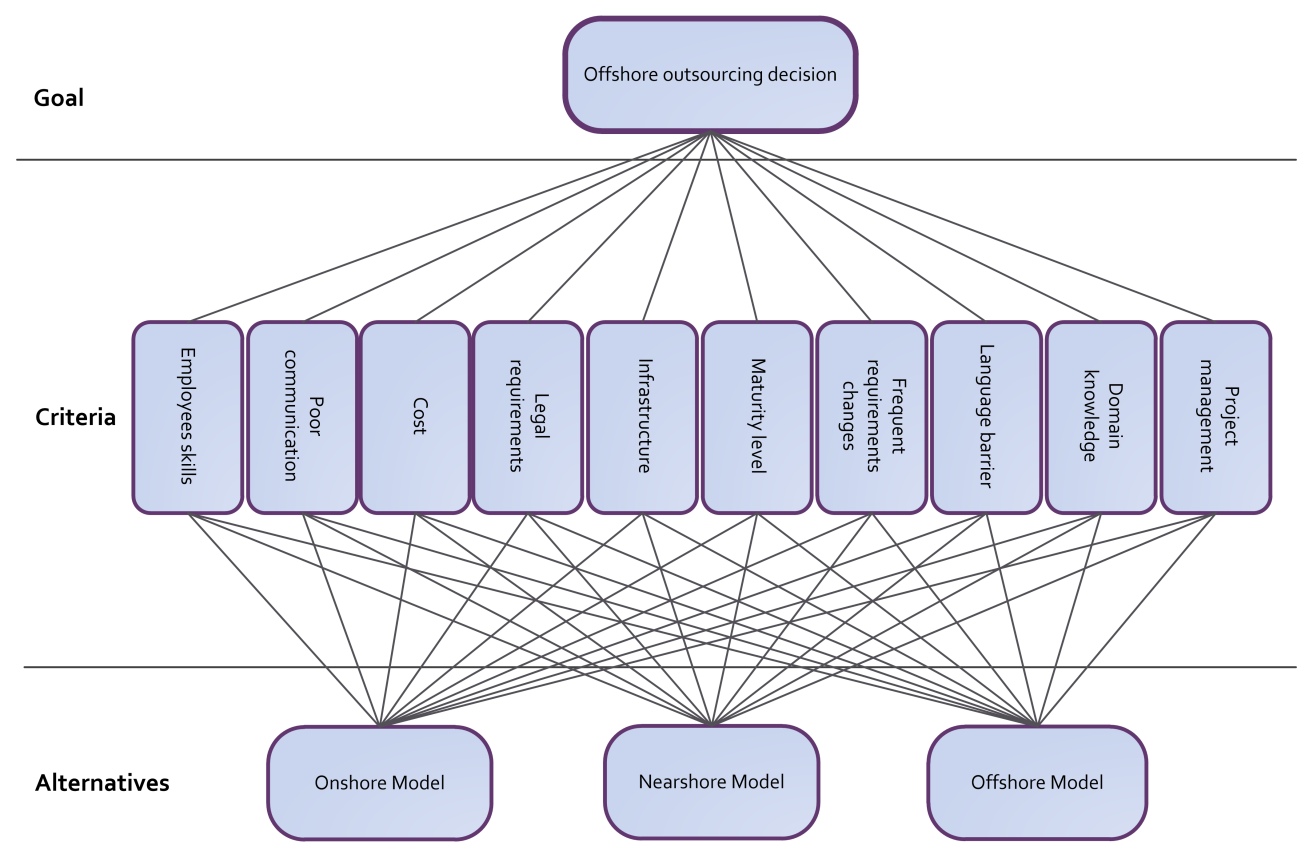

Figure 5. Hierarchical structure of the goal, criteria and alternatives.

\subsubsection{Assigning Weights to Criteria}

Using AHP, a relative score is assigned to each criterion based on its importance with respect to the goal. The level of importance is measured by comparing two criteria based on a nine-point scale as shown in Table 2. We allocate the degree of importance of one element over another to each pair. The extraordinary superiority of one criterion over another is given a score of 9 , and equality is given a score of 1 . The reciprocal value is 
added if the second factor is more relevant than the first. As a result, we find values in the range of $1 / 9$ to $9[80,81]$.

The proposed MCDM model was evaluated in the outsourcing industry by three case studies. The outcomes of these case studies were further reviewed by outsourcing specialists in other firms as well. The details of these case studies are as follows:

Case study-1: For the first case study regarding the offshore outsourcing decision of application maintenance, the input was provided by the IBM Stockholm Sweden's outsourcing expert. The input values were provided according to the project nature and its requirements. We performed the sourcing decision based on the provided input by using our proposed MCDM model for the identification of ranking of the available alternatives. The outsourcing decision was shared back with two outsourcing specialists at IBM, Stockholm, Sweden who validated the result. Similarly, an Outsourcing Strategist and Consultant at Stairo Global LLC in the United States validated the findings of the same case study.

Case study-2: Appendix A, contains the second case study (Tables A1-A7). The values for this case study were given by an IT professional at Vattenfall AB, Stockholm, Sweden. Using the MCDM model, the outsourcing decision was made based on the supplied input. The result was shared back with the IT specialist for verification, and the resulting ranking was validated. Similarly, the outcomes of this case study were further reviewed and validated by outsourcing specialists in other international companies, such as (B) Stockholm, Sweden and (C) Stockholm, Sweden.

Case study-3: The third case study was performed and evaluated in the international company (A), London, England, UK. The results of this case study were also verified by the IT professional in an international organization (D), Dublin, Ireland. In the current paper, however, we only included case studies 1 and 2.

Case study-1: The following is a full summary of the case study:

Table 4, shows the values assigned to criteria and alternatives, in this case, by an outsourcing specialist from IBM Stockholm, Sweden. The project was evaluated for the offshore outsourcing decision based on its nature and the requirements, which are given below:

The top three high requirements of the current project are the legal requirements, employee skills and cost:

- Legal requirements: This application contains high legal requirements.

- Employee skills: For the current project, the employee skills are crucial.

- Cost: This project is not very cost sensitive, i.e., the project has a reasonable budget for maintenance.

The following three requirements have a medium level of effect on sourcing decisions:

- Poor communication: Communication has a medium level of influence on the current project.

- Infrastructure: Quality of infrastructure has a medium level of influence on the current project.

- Frequent requirement changes: Frequent requirement changes also has a medium level influence on the current project.

The following three factors have low influence on the current project

- Domain knowledge: For offshore outsourcing decision of the current project, domain knowledge has low influence.

- Maturity level: For offshore outsourcing decision of the current project, maturity level has low influence.

- Project management: For offshore outsourcing decision of the current project, project management has low influence.

Finally the,

- Language barrier: The current project does not have language constraints. 
Table 4. Assigning weights to criteria with respect to the goal.

\begin{tabular}{ccccccccccc}
\hline & ES & PC & Cos & LR & Inf & ML & FRC & LB & DK & PM \\
\hline Employee skills & 1 & 2 & 1 & $1 / 3$ & 5 & 3 & 2 & 7 & 3 & 3 \\
Poor communication & $1 / 2$ & 1 & $1 / 2$ & $1 / 4$ & 3 & 2 & 1 & 5 & 2 & 2 \\
Cost & 1 & 2 & 1 & $1 / 3$ & 5 & 3 & 2 & 7 & 3 & 3 \\
Legal requirements & 3 & 4 & 3 & 1 & 7 & 5 & 4 & 9 & 5 & 5 \\
Infrastructure & $1 / 5$ & $1 / 3$ & $1 / 5$ & $1 / 7$ & 1 & $1 / 2$ & $1 / 2$ & 4 & $1 / 2$ & $1 / 2$ \\
Maturity level & $1 / 3$ & $1 / 2$ & $1 / 3$ & $1 / 5$ & 2 & 1 & 1 & 4 & 1 & 1 \\
Frequent R C & $1 / 2$ & 1 & $1 / 2$ & $1 / 4$ & 2 & 1 & 1 & 4 & 2 & $1 / 5$ \\
Language barrier & $1 / 7$ & $1 / 5$ & $1 / 7$ & $1 / 9$ & $1 / 4$ & $1 / 4$ & $1 / 4$ & 1 & $1 / 4$ & $1 / 4$ \\
Domain knowledge & $1 / 3$ & $1 / 2$ & $1 / 3$ & $1 / 5$ & 2 & 1 & $1 / 2$ & 4 & 1 & 1 \\
Project management & $1 / 3$ & $1 / 2$ & $1 / 3$ & $1 / 5$ & 2 & 1 & $1 / 2$ & 4 & 1 & 1 \\
\hline
\end{tabular}

The notable factors for this case are the legal requirements, employee skills and language barrier. This can be explained as the project has high legal requirements as well as employee skills, and it does not have a language barrier. Table 4, shows that legal requirements have high preference over other factors. Legal requirements are three-times, four-times, three-times, seven-times, five-times, four-times, nine-times, five-times and five-times important than ES, PC, Cos, Inf, ML, FRC, LB, DK and PM, respectively.

Similarly, employee skills has high priority after the legal requirements, such as ES is two-times preferred over PC and FRC; three-times over ML, DK and PM; five-times over Inf and seven-times over LB. The remaining factors are normal and do not need special care.

\subsubsection{Pairwise Comparison Matrix of Criteria}

In this step, the weight of each factor is identified to show the relative importance of each element to the others. A comparison matrix is created for the weight calculation depending on the importance given to each factor [58].

Table 5, shows the pairwise matrix of criteria labeled as A1 and the calculated weights of the criteria labeled as A2, which is the last column of Table 5. The paragraphs that follow explain the weight calculation process of the criteria.

Table 5. Pairwise comparison of the criteria.

\begin{tabular}{cccccccccccc}
\hline & & & \multicolumn{1}{c}{ A1 } & & & & & A2 \\
\hline & ES & PC & Cos & LR & Inf & ML & FRC & LB & DK & PM & Weights \\
\hline ES & 1.000 & 2.000 & 1.000 & 0.333 & 5.000 & 3.000 & 2.000 & 7.000 & 3.000 & 3.000 & 0.153 \\
PC & 0.500 & 1.000 & 0.500 & 0.250 & 3.000 & 2.000 & 1.000 & 5.000 & 2.000 & 2.000 & 0.092 \\
Cos & 1.000 & 2.000 & 1.000 & 0.333 & 5.000 & 3.000 & 2.000 & 7.000 & 3.000 & 3.000 & 0.153 \\
LR & 3.000 & 4.000 & 3.000 & 1.000 & 7.000 & 5.000 & 4.000 & 9.000 & 5.000 & 5.000 & 0.302 \\
Inf & 0.200 & 0.333 & 0.200 & 0.143 & 1.000 & 0.500 & 0.500 & 4.000 & 0.500 & 0.500 & 0.035 \\
ML & 0.333 & 0.500 & 0.333 & 0.200 & 2.000 & 1.000 & 1.000 & 4.000 & 1.000 & 1.000 & 0.059 \\
FRC & 0.500 & 1.000 & 0.500 & 0.250 & 2.000 & 1.000 & 1.000 & 4.000 & 2.000 & 2.000 & 0.080 \\
LB & 0.143 & 0.200 & 0.143 & 0.111 & 0.250 & 0.250 & 0.250 & 1.000 & 0.250 & 0.250 & 0.017 \\
DK & 0.333 & 0.500 & 0.333 & 0.200 & 2.000 & 1.000 & 0.500 & 4.000 & 1.000 & 1.000 & 0.055 \\
PM & 0.333 & 0.500 & 0.333 & 0.200 & 2.000 & 1.000 & 0.500 & 4.000 & 1.000 & 1.000 & 0.055 \\
\hline
\end{tabular}

The calculated weights of the criteria are given in Table 5, column (A2), which shows that the factor legal requirements had the highest priority (30.2\%) among all the influencing factors. Similarly, the cost and employee skills received high priority after the legal requirements with equal weights of $15.3 \%$. Other notable factors were poor communication and frequent requirement changes with priorities of $9.2 \%$ and $8 \%$, respectively. Both domain knowledge and project management had the same level of importance as each had 5.5\% priority. The step-by-step calculation of the weights of the criteria is given in Table 6 . 
Table 6. Step by step calculations of criteria weight.

\begin{tabular}{cllll}
\hline ES & {$\left[1.000^{*} 2.000^{*} 1.000^{*} 0.333^{*} 5.000^{*} 3.000^{*} 2.000^{*} 7.000^{*} 3.000^{*} 3.000\right] 1 / 10=2.042$} & $2.042 / 13.3571$ & 0.153 \\
PC & {$\left[0.500^{*} 1.000^{*} 0.500^{*} 0.250^{*} 3.000^{*} 2.000^{*} 1.000^{*} 5.000^{*} 2.000^{*} 2.000\right] 1 / 10=1.223$} & $1.223 / 13.3571$ & 0.092 \\
Cos & {$\left[1.000^{*} 2.000^{*} 1.000^{*} 0.333^{*} 5.000^{*} 3.000^{*} 2.000^{*} 7.000^{*} 3.000^{*} 3.000\right] 1 / 10=2.042$} & $2.042 / 13.3571$ & 0.153 \\
LR & {$\left[3.000^{*} 4.000^{*} 3.000^{*} 1.000^{*} 7.000^{*} 5.000^{*} 4.000^{*} 9.000^{*} 5.000^{*} 5.000\right] 1 / 10=4.031$} & $4.031 / 13.3571$ & 0.302 \\
Inf & {$\left[0.200^{*} 0.333^{*} 0.200^{*} 0.143^{*} 1.000^{*} 0.500^{*} 0.500^{*} 4.000^{*} 0.500^{*} 0.500\right] 1 / 10=0.465$} & $0.465 / 13.3571$ & 0.035 \\
ML & {$\left[0.333^{*} 0.500^{*} 0.333^{*} 0.200^{*} 2.000^{*} 1.000^{*} 1.000^{*} 4.000^{*} 1.000^{*} 1.000\right] 1 / 10=0.785$} & $0.785 / 13.3571$ & 0.059 \\
FRC & {$\left[0.500^{*} 1.000^{*} 0.500^{*} 0.250^{*} 2.000^{*} 1.000^{*} 1.000^{*} 4.000^{*} 2.000^{*} 2.000\right] 1 / 10=1.072$} & $1.072 / 13.3571$ & 0.080 \\
LB & {$\left[0.143^{*} 0.200^{*} 0.143^{*} 0.111^{*} 0.250^{*} 0.250^{*} 0.250^{*} 1.000^{*} 0.250^{*} 0.250\right] 1 / 10=0.232$} & $0.232 / 13.3571$ & 0.017 \\
DK & {$\left[0.333^{*} 0.500^{*} 0.333^{*} 0.200^{*} 2.000^{*} 1.000^{*} 0.500^{*} 4.000^{*} 1.000^{*} 1.000\right] 1 / 10=0.732$} & $0.732 / 13.3571$ & 0.055 \\
PM & {$\left[0.333^{*} 0.500^{*} 0.333^{*} 0.200^{*} 2.000^{*} 1.000^{*} 0.500^{*} 4.000^{*} 1.000^{*} 1.000\right] 1 / 10=0.732$} & $0.732 / 13.3571$ & 0.055 \\
\hline \multicolumn{5}{c}{ Sum $=13.3571$} \\
\hline
\end{tabular}

\subsubsection{Calculating the Index Ratio and Consistency Ratio}

The word "consistency" refers to determining whether a pairwise relation is consistent. Similarly, AHP provides the Consistency Ratio (CR) as the measurement of consistency for pairwise comparisons. The pairwise comparison is considered inconsistent if the CR is greater than 0.10 . Whereas, a value less than 0.10 means that the result of pairwise comparison is acceptable [52,57].

The CI and CR were calculated using Equations (1) and (2).

$$
C I=\frac{(\Lambda \max -n)}{(n-1)}
$$

where $n$ is the number of factors in the data set. We used 10 critical success factors in this research.

CR is achieved by dividing the Consistency Index by the Random Consistency Index (RI), and the values of RI are given in Table A8 in Appendix A.

$$
C R=\frac{C I}{R I}
$$

In order to calculate the consistency ratio, we need to compute the Lambda max value. The Lambda max value is achieved as $\mathrm{A} 1 \times \mathrm{A} 2=\mathrm{A} 3 \rightarrow \mathrm{A} 3 \div \mathrm{A} 2 \rightarrow \mathrm{A} 4 \rightarrow$ Average of $\mathrm{A} 4 \rightarrow$ Lambda max. The step by step calculation of the Lambda max value is given in Table 7 .

\begin{tabular}{|c|c|c|c|c|c|c|c|c|c|c|c|c|c|}
\hline & & & & & A1 & & & & & & A2 & A3 & A4 \\
\hline & ES & PC & Cos & LR & Inf & ML & FRC & LB & DK & $\mathbf{P M}$ & & & \\
\hline ES & 1.000 & 2.000 & 1.000 & 0.333 & 5.000 & 3.000 & 2.000 & 7.000 & 3.000 & 3.000 & 0.153 & 1.551 & 10.145 \\
\hline PC & 0.500 & 1.000 & 0.500 & 0.250 & 3.000 & 2.000 & 1.000 & 5.000 & 2.000 & 2.000 & 0.092 & 0.928 & 10.136 \\
\hline Cos & 1.000 & 2.000 & 1.000 & 0.333 & 5.000 & 3.000 & 2.000 & 7.000 & 3.000 & 3.000 & 0.153 & 1.551 & 10.145 \\
\hline LR & 3.000 & 4.000 & 3.000 & 1.000 & 7.000 & 5.000 & 4.000 & 9.000 & 5.000 & 5.000 & 0.302 & 3.148 & 10.431 \\
\hline Inf & 0.200 & 0.333 & 0.200 & 0.143 & 1.000 & 0.500 & 0.500 & 4.000 & 0.500 & 0.500 & 0.035 & 0.363 & 10.428 \\
\hline ML & 0.333 & 0.500 & 0.333 & 0.200 & 2.000 & 1.000 & 1.000 & 4.000 & 1.000 & 1.000 & 0.059 & 0.596 & 10.137 \\
\hline FRC & 0.500 & 1.000 & 0.500 & 0.250 & 2.000 & 1.000 & 1.000 & 4.000 & 2.000 & 2.000 & 0.080 & 0.817 & 10.185 \\
\hline LB & 0.143 & 0.200 & 0.143 & 0.111 & 0.250 & 0.250 & 0.250 & 1.000 & 0.250 & 0.250 & 0.017 & 0.184 & 10.600 \\
\hline DK & 0.333 & 0.500 & 0.333 & 0.200 & 2.000 & 1.000 & 0.500 & 4.000 & 1.000 & 1.000 & 0.055 & 0.556 & 10.133 \\
\hline PM & 0.333 & 0.500 & 0.333 & 0.200 & 2.000 & 1.000 & 0.500 & 4.000 & 1.000 & 1.000 & 0.055 & 0.556 & 10.133 \\
\hline
\end{tabular}

Table 7. Calculation of the Lambda max value.

Thus, the Lambda max value is $(\Lambda \max )=10.247$.

Equation (1) is used to calculate the consistency index as given below.

$$
C I=\frac{10.247-10}{10-1}=0.027
$$


Similarly, Equation (2) is used to measure the consistency ratio as shown below.

$$
C R=\frac{0.027}{1.49}=0.018
$$

Hence, the $C R$ value is less than 0.1 , which is acceptable.

\subsubsection{Calculating the Alternatives Weights with Respect to the Criteria}

This section presents the comparison of alternatives with respect to each criterion. The level of significance for each alternative is calculated on the scale of 1-9 points as given in Table 2 [81]. The steps for calculating the weights of criteria and computing their consistency ratios were already discussed in Sections 4.2 .3 and 4.2.4, respectively. Hence, Tables $8-12$ provide only the assigned scores for the alternatives, their associated weights and consistency ratios.

Table 8. Weights of the alternatives with respect to employee skills and poor communication.

\begin{tabular}{|c|c|c|c|c|c|c|c|c|c|}
\hline ES & OM & $\mathbf{N M}$ & OfM & Weights & PC & OM & NM & OfM & Weights \\
\hline $\begin{array}{l}\text { Onshore } \\
\text { Model }\end{array}$ & 1.000 & 0.333 & 0.200 & 0.114 & $\begin{array}{l}\text { Onshore } \\
\text { Model }\end{array}$ & 1.000 & 1.000 & 3.000 & 0.443 \\
\hline $\begin{array}{l}\text { Nearshore } \\
\text { Model }\end{array}$ & 3.000 & 1.000 & 1.000 & 0.405 & $\begin{array}{l}\text { Nearshore } \\
\text { Model }\end{array}$ & 1.000 & 1.000 & 2.000 & 0.387 \\
\hline $\begin{array}{l}\text { Offshore } \\
\text { Model }\end{array}$ & 5.000 & 1.000 & 1.000 & 0.481 & $\begin{array}{l}\text { Offshore } \\
\text { Model }\end{array}$ & 0.333 & 0.500 & 1.000 & 0.169 \\
\hline \multicolumn{5}{|c|}{$\Lambda \max =3.028, C . I=0.014, C . R=0.027<0.1$} & \multicolumn{5}{|c|}{$\Lambda \max =3.022, \mathrm{C} . \mathrm{I}=0.011, \mathrm{C} . \mathrm{R}=0.021<0.1$} \\
\hline
\end{tabular}

Table 9. Weights of the alternatives with respect to costs and legal requirements.

\begin{tabular}{|c|c|c|c|c|c|c|c|c|c|}
\hline Cost & OM & NM & OfM & Weights & LR & OM & NM & OfM & Weights \\
\hline \multirow{3}{*}{$\begin{array}{l}\text { Onshore } \\
\text { Model } \\
\text { Nearshore } \\
\text { Model } \\
\text { Offshore } \\
\text { Model }\end{array}$} & 1.000 & 0.500 & 0.200 & 0.128 & $\begin{array}{l}\text { Onshore } \\
\text { Model }\end{array}$ & 1.000 & 3.000 & 7.000 & 0.669 \\
\hline & 2.000 & 1.000 & & 0.276 & $\begin{array}{l}\text { Nearshore } \\
\text { Model }\end{array}$ & 0.333 & 1.000 & 3.000 & 0.243 \\
\hline & 5.000 & 2.000 & 1.000 & 0.595 & $\begin{array}{l}\text { Offshore } \\
\text { Model }\end{array}$ & 0.143 & 0.333 & 1.000 & 0.088 \\
\hline \multicolumn{5}{|c|}{$\Lambda \max =3.011, \mathrm{C} . \mathrm{I}=0.006, \mathrm{C} . \mathrm{R}=0.011<0.1$} & \multicolumn{5}{|c|}{$\Lambda \max =3.004$, C.I $=0.002, C . R=0.004<0.1$} \\
\hline
\end{tabular}

Table 10. Weights of the alternatives with respect to the infrastructure and maturity level.

\begin{tabular}{|c|c|c|c|c|c|c|c|c|c|}
\hline Inf & OM & NM & OfM & Weights & ML & OM & NM & OfM & Weights \\
\hline $\begin{array}{l}\text { Onshore } \\
\text { Model }\end{array}$ & 1.000 & 1.000 & 2.000 & 0.400 & $\begin{array}{l}\text { Onshore } \\
\text { Model }\end{array}$ & 1.000 & 1.000 & 2.000 & 0.413 \\
\hline $\begin{array}{l}\text { Nearshore } \\
\text { Model }\end{array}$ & 1.000 & 1.000 & 2.000 & 0.400 & $\begin{array}{l}\text { Nearshore } \\
\text { Model }\end{array}$ & 1.000 & 1.000 & 1.000 & 0.327 \\
\hline $\begin{array}{l}\text { Offshore } \\
\text { Model }\end{array}$ & 0.500 & 0.500 & 1.000 & 0.200 & $\begin{array}{l}\text { Offshore } \\
\text { Model }\end{array}$ & 0.500 & 1.000 & 1.000 & 0.260 \\
\hline \multicolumn{5}{|c|}{$\Lambda \max =3.000$, C.I $=0.000$, C.R $=0.000<0.1$} & \multicolumn{5}{|c|}{$\Lambda \max =3.054$, C.I $=0.027, C . R=0.052<0.1$} \\
\hline
\end{tabular}

Table 11. Weights of the alternatives with respect to frequent requirement changes and language barriers.

\begin{tabular}{|c|c|c|c|c|c|c|c|c|c|}
\hline FRC & OM & NM & OfM & Weights & LB & OM & NM & OfM & Weights \\
\hline \multirow{3}{*}{$\begin{array}{l}\text { Onshore } \\
\text { Model } \\
\text { Nearshore } \\
\text { Model } \\
\text { Offshore } \\
\text { Model }\end{array}$} & 1.000 & 1.000 & 3.000 & 0.443 & $\begin{array}{l}\text { Onshore } \\
\text { Model }\end{array}$ & 1.000 & 1.000 & 1.000 & 0.333 \\
\hline & 1.000 & 1.000 & 2.000 & 0.387 & $\begin{array}{l}\text { Nearshore } \\
\text { Model }\end{array}$ & 1.000 & 1.000 & 1.000 & 0.333 \\
\hline & 0.333 & 0.500 & 1.000 & 0.169 & $\begin{array}{l}\text { Offshore } \\
\text { Model }\end{array}$ & 1.000 & 1.000 & 1.000 & 0.333 \\
\hline \multicolumn{5}{|c|}{$\Lambda \max =3.022, \mathrm{C} . \mathrm{I}=0.011, \mathrm{C} . \mathrm{R}=0.021<0.1$} & $\Lambda \max =3$ & C. $I=$ & O2C.R & $.003<$ & \\
\hline
\end{tabular}


Table 12. Weights of the alternatives with respect to domain knowledge and project management.

\begin{tabular}{|c|c|c|c|c|c|c|c|c|c|}
\hline DK & OM & NM & OfM & Weights & PM & OM & NM & OfM & Weights \\
\hline $\begin{array}{l}\text { Onshore } \\
\text { Model }\end{array}$ & 1.000 & 1.000 & 1.000 & 0.333 & $\begin{array}{l}\text { Onshore } \\
\text { Model }\end{array}$ & 1.000 & 2.000 & 2.000 & 0.500 \\
\hline $\begin{array}{l}\text { Nearshore } \\
\text { Model }\end{array}$ & 1.000 & 1.000 & 1.000 & 0.333 & $\begin{array}{l}\text { Nearshore } \\
\text { Model }\end{array}$ & 0.500 & 1.000 & 1.000 & 0.250 \\
\hline $\begin{array}{l}\text { Offshore } \\
\text { Model }\end{array}$ & 1.000 & 1.000 & 1.000 & 0.333 & $\begin{array}{l}\text { Offshore } \\
\text { Model }\end{array}$ & 0.500 & 1.000 & 1.000 & 0.250 \\
\hline \multicolumn{5}{|c|}{$\Lambda \max =3.003$, C.I $=0.002$, C.R $=0.003<0.1$} & \multicolumn{5}{|c|}{$\Lambda \max =3.000$, C.I $=0.000$, C.R $=0.000<0.1$} \\
\hline
\end{tabular}

\subsubsection{Decision Matrix}

This segment presents the calculation of final ranking of alternatives regarding the offshore outsourcing decision of application maintenance. The final ranking of the sourcing alternatives (onshore model, nearshore model and offshore model) was determined by combining the calculated weights of the criteria and alternatives in Sections 4.2.3 and 4.2.5 respectively. The ranking of alternatives, as well as the overall ranking calculation, are shown in Table 13 and Figure 6.

Table 13. Decision Matrix: calculating the ranking of alternatives.

\begin{tabular}{|c|c|c|c|c|c|c|c|}
\hline \multirow{2}{*}{ Critical Success Factors } & \multirow{2}{*}{$\begin{array}{l}\text { Weights } \\
\text { (Wc) }\end{array}$} & \multicolumn{2}{|c|}{ Onshore Model } & \multicolumn{2}{|c|}{ Nearshore Model } & \multicolumn{2}{|c|}{ Offshore Model } \\
\hline & & Wa & $\mathbf{W c} \mathbf{c}^{*} \mathbf{W a}$ & Wa & $\mathbf{W c} c^{*} \mathbf{W a}$ & Wa & $\mathbf{W c} c^{*} \mathbf{a}$ \\
\hline Employee skills & 0.153 & 0.114 & $0.153^{*} 0.114=$ & 0.405 & $0.405^{*} 0.153=$ & 0.481 & $0.481^{*} 0.153$ \\
\hline Poor communication & 0.092 & 0.443 & $0.092 * 0.443=$ & 0.387 & $0.387^{*} 0.092=$ & 0.169 & $0.169^{*} 0.092$ \\
\hline Cost & 0.153 & 0.128 & $0.153^{*} 0.128=$ & 0.276 & $0.276^{*} 0.153=$ & 0.595 & $0.595^{*} 0.153$ \\
\hline Legal requirements & 0.302 & 0.669 & $0.302 * 0.669=$ & 0.243 & $0.243^{*} 0.302=$ & 0.088 & $0.088^{*} 0.302$ \\
\hline Infrastructure & 0.035 & 0.400 & $0.035^{*} 0.400=$ & 0.400 & $0.400 * 0.035=$ & 0.200 & $0.200^{*} 0.035$ \\
\hline Maturity level & 0.059 & 0.413 & $0.059^{*} 0.413=$ & 0.327 & $0.327^{*} 0.059=$ & 0.260 & $0.260^{*} 0.059$ \\
\hline $\begin{array}{l}\text { Frequent requirements } \\
\text { changes }\end{array}$ & 0.080 & 0.443 & $0.080^{*} 0.443=$ & 0.387 & $0.387^{*} 0.080=$ & 0.169 & $0.169^{*} 0.080$ \\
\hline Language barrier & 0.017 & 0.333 & $0.017^{*} 0.333=$ & 0.333 & $0.333^{*} 0.017=$ & 0.333 & $0.333^{*} 0.017$ \\
\hline Domain knowledge & 0.055 & 0.333 & $0.055^{*} 0.333=$ & 0.333 & $0.333^{*} 0.055=$ & 0.333 & $0.333^{*} 0.055$ \\
\hline $\begin{array}{l}\text { Project } \\
\text { management }\end{array}$ & 0.055 & 0.500 & $0.055^{*} 0.413=$ & 0.250 & $0.327^{*} 0.055=$ & 0.250 & $0.260 * 0.055$ \\
\hline Alternatives' ranking & & & 0.405 & & 0.315 & & 0.280 \\
\hline
\end{tabular}

Table 13, shows the overall ranking of the sourcing alternatives. The onshore model had the highest value, i.e., $40.5 \%$. Clearly, this was the most appropriate alternative among the available models for application maintenance. Similarly, the nearshore model stands on the second position with $31.5 \%$ of priority, whereas the offshore model remained on third position by having a priority of $28 \%$.

Similarly, our proposed MCDM model ranked the sourcing alternatives for application maintenance offshoring as shown in Figure 6. The priorities of the sourcing alternatives were calculated for case study-1. For this case study, the criteria scores and alternative values are presented according to the nature of the project and client's requirements by an application maintenance expert of IBM Stockholm, Sweden. Based on the provided input of the project regarding the offshore outsourcing decision, the onshore model was ranked first among the available alternatives. 


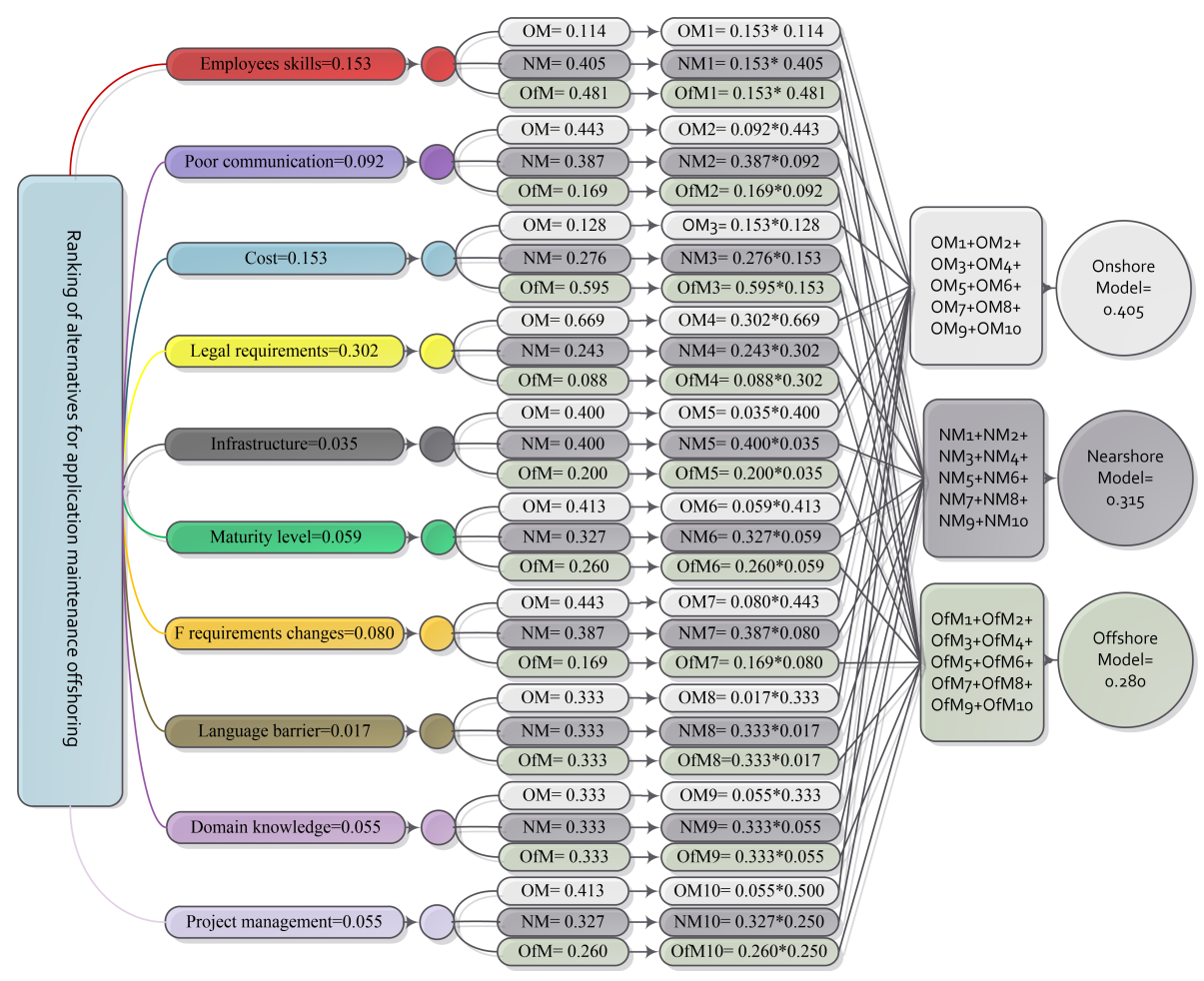

Figure 6. Ranking of sourcing alternatives.

\section{Conclusions and Future Work}

By adopting an offshore outsourcing strategy, a vendor offers low cost services across national boundaries. Global services are provided by selecting one of the suitable global delivery options, such as the onshore model, nearshore model and offshore model. Therefore, the current study introduced a MCDM approach for choosing effective and appropriate sourcing models. A sourcing framework was proposed based on the identified critical success factors.

The suggested framework can be used by clients as well as on the vendor side to assess the project's nature and requirements. By using the proposed sourcing framework, a project can be evaluated prior to sourcing decisions by examining all the critical success factors. As a result of the project's evaluation on the basis of "Yes" and "No", the preferences of alternatives for sourcing decisions are derived.

In order to further enhance the decision-making process of application maintenance offshoring, the MCDM model was developed. The proposed model is used to rank the sourcing alternatives and suggest the most suitable option. It takes input from the experts for each criterion and alternative and ranks the sourcing alternatives accordingly. Hence, the proposed model is used as a decision support system that assists practitioners and IT experts in selecting the most appropriate sourcing strategy.

Similarly, it enables decision makers to take effective and appropriate application offshoring decisions. The developed MCDM model was evaluated with three case studies in the outsourcing industry. The obtained results, i.e., rankings of alternatives, were further reviewed and validated by outsourcing specialists in other companies.

It would be interesting to convert the developed MCDM model into a tool in the near future by utilizing an appropriate programming language, such as Javascript. The constructed tool will be available online that will help the decision makers and practitioners in making the sourcing decisions. The tool will make calculations based on the provided input, such as the weight calculation of factors and alternatives, and will consequently rank the alternatives. 
Similarly, we would like to expand the scope of the developed MCDM model by incorporating more alternative options and implementing a different multi-criteria decisionmaking approach, such as Analytic Network Hierarchy (ANP), Fuzzy logic and Fuzzy AHP.

Author Contributions: Conceptualization, H.U.R., M.R. and P.A.; methodology, H.A., A.A. and S.A.; validation, H.A., M.R., P.A. and S.A.; formal analysis, H.U.R.; investigation, H.U.R.; data curation, H.A. and M.R.; writing—original draft preparation, H.U.R.; writing—review and editing, H.U.R.; supervision, M.R. and P.A.; funding acquisition, A.A. All authors have read and agreed to the published version of the manuscript.

Funding: This research received no external funding.

Acknowledgments: This research was supported by Taif University Researchers Supporting Project number (TURSP-2020/231), Taif University, Taif, Saudi Arabia.

Conflicts of Interest: The authors declare no conflict of interest.

\section{Appendix A}

Case study-2: Tables A1-A7.

Table A8, shows the Random Consistency Index values.

Table A1. Case study-2: Pairwise comparison of criteria.

\begin{tabular}{cccccccccccc}
\hline & \multicolumn{10}{c}{ A1 } & A2 \\
\hline & ES & PC & Cos & LR & Inf & ML & FRC & LB & DK & PM & Weights \\
\hline ES & 1.000 & 6.000 & 0.500 & 8.000 & 3.000 & 2.000 & 4.000 & 8.000 & 7.000 & 5.000 & 0.223 \\
PC & 0.167 & 1.000 & 0.143 & 2.000 & 0.500 & 0.200 & 0.500 & 2.000 & 1.000 & 1.000 & 0.039 \\
Cos & 2.000 & 7.000 & 1.000 & 9.000 & 4.000 & 3.000 & 5.000 & 9.000 & 8.000 & 6.000 & 0.302 \\
LR & 0.125 & 0.500 & 0.111 & 1.000 & 0.200 & 0.167 & 0.200 & 1.000 & 0.500 & 0.200 & 0.02 \\
Inf & 0.333 & 2.000 & 0.250 & 5.000 & 1.000 & 0.500 & 1.000 & 5.000 & 4.000 & 2.000 & 0.089 \\
ML & 0.500 & 5.000 & 0.333 & 6.000 & 2.000 & 1.000 & 2.000 & 6.000 & 5.000 & 2.000 & 0.137 \\
FRC & 0.250 & 2.000 & 0.200 & 5.000 & 1.000 & 0.500 & 1.000 & 5.000 & 4.000 & 1.000 & 0.079 \\
LB & 0.125 & 0.500 & 0.111 & 1.000 & 0.200 & 0.167 & 0.200 & 1.000 & 0.500 & 0.200 & 0.02 \\
DK & 0.143 & 1.000 & 0.125 & 2.000 & 0.250 & 0.200 & 0.250 & 2.000 & 1.000 & 1.000 & 0.033 \\
PM & 0.200 & 1.000 & 0.167 & 5.000 & 0.500 & 0.500 & 1.000 & 5.000 & 1.000 & 1.000 & 0.058 \\
\hline & \multicolumn{10}{c}{$\Lambda$ max $=10.371$, C.I $=0.041$, C.R $=0.028$} \\
\hline
\end{tabular}

Table A2. Case study-2: Calculation of alternative preferences with respect to employee skills and poor communication.

\begin{tabular}{cccccccccc}
\hline Employee Skills & OM & NM & OfM & Wt & Poor Communication & OM & NM & OfM & Wt \\
\hline OM & 1.000 & 0.333 & 0.167 & 0.095 & OM & 1.000 & 1.000 & 3.000 & 0.443 \\
NM & 3.000 & 1.000 & 0.333 & 0.250 & NM & 1.000 & 1.000 & 2.000 & 0.387 \\
OfM & 6.000 & 3.000 & 1.000 & 0.655 & OfM & 0.333 & 0.500 & 1.000 & 0.169 \\
\hline$\Lambda \max =3.021$, C.I $=0.011$, C.R $=0.021<0.1$ & \multicolumn{2}{c}{$\Lambda \max =3.022$, C.I $=0.011$, C.R $=0.021<0.1$} & \\
\hline
\end{tabular}

Table A3. Case study-2: Calculation of alternative preferences with respect to costs and legal requirements.

\begin{tabular}{cccccccccc}
\hline Cost & OM & NM & OfM & Wt & Legal Requirements & OM & NM & OfM & Wt \\
\hline Onshore Model & 1.000 & 0.250 & 0.125 & 0.070 & Onshore Model & 1.000 & 1.000 & 1.000 & 0.333 \\
Nearshore Model & 4.000 & 1.000 & 0.250 & 0.223 & Nearshore Model & 1.000 & 1.000 & 1.000 & 0.333 \\
Offshore Model & 8.000 & 4.000 & 1.000 & 0.707 & Offshore Model & 1.000 & 1.000 & 1.000 & 0.333 \\
\hline
\end{tabular}

$\Lambda \max =3.052$, C.I $=0.026$, C.R $=0.050<0.1$

$\Lambda \max =3.003$, C.I $=0.002$, C.R $=0.003<0.1$ 
Table A4. Case study-2: Calculation of alternative preferences with respect to infrastructure and maturity level.

\begin{tabular}{cccccccccc}
\hline Infrastructure & OM & NM & OfM & Wt & Maturity Level & OM & NM & OfM & Wt \\
\hline Onshore Model & 1.000 & 0.500 & 0.250 & 0.136 & Onshore Model & 1.000 & 1.000 & 0.200 & 0.156 \\
Nearshore Model & 2.000 & 1.000 & 0.333 & 0.238 & Nearshore Model & 1.000 & 1.000 & 0.333 & 0.185 \\
Offshore Model & 4.000 & 3.000 & 1.000 & 0.625 & Offshore Model & 5.000 & 3.000 & 1.000 & 0.659 \\
\hline
\end{tabular}

$\Lambda \max =3.024$, C.I $=0.012$, C.R $=0.023$

$\Lambda \max =3.031$, C.I $=0.015$, C.R $=0.029<0.1$

Table A5. Case study-2: Calculation of alternative preferences with respect to frequent requirement changes and language barrier.

\begin{tabular}{cccccccccc}
\hline $\begin{array}{c}\text { Frequent Requirements } \\
\text { Changes }\end{array}$ & OM & NM & OfM & Wt & Language Barrier & OM & NM & OfM & Wt \\
\hline Onshore Model & 1.000 & 2.000 & 3.000 & 0.550 & Onshore Model & 1.000 & 1.000 & 1.000 & 0.333 \\
Nearshore Model & 0.500 & 1.000 & 1.000 & 0.240 & Nearshore Model & 1.000 & 1.000 & 1.000 & 0.333 \\
Offshore Model & 0.333 & 1.000 & 1.000 & 0.210 & Offshore Model & 1.000 & 1.000 & 1.000 & 0.333 \\
\hline \multicolumn{1}{c}{$\Lambda$ max $=3.018$, C.I $=0.009$, C.R $=0.017<0.1$} & \multicolumn{1}{c}{$\Lambda \max =3.003$, C.I $=0.002$, C.R $=0.003<0.1$} \\
\hline
\end{tabular}

Table A6. Case study-2: Calculation of alternative preferences with respect to domain knowledge and project management.

\begin{tabular}{cccccccccc}
\hline Domain Knowledge & OM & NM & OfM & Wt & Project Management & OM & NM & OfM & Wt \\
\hline Onshore Model & 1.000 & 1.000 & 0.500 & 0.260 & Onshore Model & 1.000 & 1.000 & 0.500 & 0.260 \\
Nearshore Model & 1.000 & 1.000 & 1.000 & 0.327 & Nearshore Model & 1.000 & 1.000 & 1.000 & 0.327 \\
Offshore Model & 2.000 & 1.000 & 1.000 & 0.413 & Offshore Model & 2.000 & 1.000 & 1.000 & 0.413 \\
\hline \multicolumn{1}{c}{$\Lambda$ max $=3.054$, C.I $=0.027$, C.R $=0.052<0.1$} & \multicolumn{1}{c}{$\Lambda$ max $=3.054$, C.I $=0.027$, C.R $=0.052<0.1$} \\
\hline
\end{tabular}

Table A7. Case study-2: Decision matrix.

\begin{tabular}{|c|c|c|c|c|c|c|c|}
\hline \multirow{2}{*}{ Critical Success Factors } & \multirow{2}{*}{$\begin{array}{l}\text { Wt } \\
\text { Wc }\end{array}$} & \multicolumn{2}{|c|}{ Onshore Model } & \multicolumn{2}{|c|}{ Nearshore Model } & \multicolumn{2}{|c|}{ Offshore Model } \\
\hline & & Weight (Wa) & Total $\left(W^{*} \mathbf{W a}^{*}\right)$ & Weight (Wa) & Total $\left(W^{*}\right.$ Wa) & Weight (Wa) & Total $\left(\mathrm{Wc}^{*} \mathrm{Wa}\right)$ \\
\hline Employee skills & 0.223 & 0.095 & $0.223^{*} 0.095$ & 0.250 & $0.223^{*} 0.250$ & 0.655 & $0.223^{*} 0.655$ \\
\hline $\begin{array}{c}\text { Poor } \\
\text { communication }\end{array}$ & 0.039 & 0.443 & $0.039 * 0.443$ & 0.387 & $0.039 * 0.387$ & 0.169 & $0.039 * 0.169$ \\
\hline Cost & 0.302 & 0.070 & $0.302 * 0.070$ & 0.223 & $0.302 * 0.223$ & 0.707 & $0.302 * 0.707$ \\
\hline $\begin{array}{l}\text { Legal } \\
\text { requirements }\end{array}$ & 0.020 & 0.333 & $0.020 * 0.333$ & 0.333 & $0.020 * 0.333$ & 0.333 & $0.020 * 0.333$ \\
\hline Infrastructure & 0.089 & 0.136 & $0.089 * 0.136$ & 0.238 & $0.089^{*} 0.238$ & 0.625 & $0.089 * 0.625$ \\
\hline Maturity level & 0.137 & 0.156 & $0.137^{*} 0.156$ & 0.185 & $0.137^{*} 0.185$ & 0.659 & $0.137^{*} 0.659$ \\
\hline $\begin{array}{l}\text { Frequent requirements } \\
\text { changes }\end{array}$ & 0.079 & 0.550 & $0.079 * 0.550$ & 0.240 & $0.079 * 0.240$ & 0.210 & $0.079 * 0.210$ \\
\hline Language barrier & 0.020 & 0.333 & $0.020 * 0.333$ & 0.333 & $0.020 * 0.333$ & 0.333 & $0.020 * 0.333$ \\
\hline Domain knowledge & 0.033 & 0.260 & $0.033^{*} 0.260$ & 0.327 & $0.333^{*} 0.327$ & 0.413 & $0.333^{*} 0.413$ \\
\hline Project management & 0.058 & 0.260 & $0.058 * 0.260$ & 0.327 & $0.058^{*} 0.327$ & 0.413 & $0.058^{*} 0.413$ \\
\hline Raking of Alternatives & & \multicolumn{2}{|c|}{0.174} & \multicolumn{2}{|c|}{0.247} & \multicolumn{2}{|c|}{0.579} \\
\hline
\end{tabular}

Table A8. Table for random index (RI) values.

\begin{tabular}{ccccccccccc}
\hline $\mathbf{N}$ & $\mathbf{1}$ & $\mathbf{2}$ & $\mathbf{3}$ & $\mathbf{4}$ & $\mathbf{5}$ & $\mathbf{6}$ & $\mathbf{7}$ & $\mathbf{8}$ & $\mathbf{9}$ & $\mathbf{1 0}$ \\
\hline Random Index & 0 & 0 & 0.52 & 0.89 & 1.11 & 1.25 & 1.35 & 1.40 & 1.45 & 1.49 \\
\hline
\end{tabular}




\section{References}

1. Rahman, H.U.; Raza, M.; Afsar, P.; Khan, H.U. Empirical Investigation of Influencing Factors Regarding Offshore Outsourcing Decision of Application Maintenance. IEEE Access 2021, 9, 58589-58608. [CrossRef]

2. Rahman, H.U.; Raza, M.; Afsar, P.; Khan, M.; Iqbal, N.; Khan, H.U. Making the Sourcing Decision of Software Maintenance and Information Technology. IEEE Access 2021, 9, 11492-11510. [CrossRef]

3. Rahman, H.U.; Raza, M.; Afsar, P.; Khan, H.U.; Nazir, S. Analyzing Factors That Influence Offshore Outsourcing Decision of Application Maintenance. IEEE Access 2020, 8, 183913-183926. [CrossRef]

4. Khan, J.A.; Khan, S.U.R.; Iqbal, J.; Rehman, I.U. Empirical Investigation About the Factors Affecting the Cost Estimation in Global Software Development Context. IEEE Access 2021, 9, 22274-22294. [CrossRef]

5. Khan, R.A.; Idris, M.Y.; Khan, S.U.; Ilyas, M.; Ali, S.; Din, A.D.; Murtaza, G.; Khan, A.W.; Jan, S.U. An Evaluation Framework for Communication and Coordination Processes in Offshore Software Development Outsourcing Relationship: Using Fuzzy Methods. IEEE Access 2019, 7, 112879-112906. [CrossRef]

6. Ali, S.; Ullah, N.; Abrar, M.F.; Majeed, M.F.; Umar, M.A.; Huang, J. Barriers to Software Outsourcing Partnership Formation: An Exploratory Analysis. IEEE Access 2019, 7, 164556-164594. [CrossRef]

7. Babar, M.A.; Verner, J.M.; Nguyen, P.T. Establishing and maintaining trust in software outsourcing relationships: An empirical investigation. J. Syst. Softw. 2007, 80, 1438-1449. [CrossRef]

8. Lacity, M.C.; Khan, S.A.; Yan, A. Review of the empirical business services sourcing literature: An update and future directions. J. Inf. Technol. 2016, 31, 269-328. [CrossRef]

9. Juga, J.; Juntunen, J.; Grant, D.B. Service quality and its relation to satisfaction and loyalty in logistics outsourcing relationships Manag. Serv. Qual. Int. J. 2010, 20, 496-510. [CrossRef]

10. Ogheneovo; Erhieyovwe, E. Software Maintenance and Evolution: The Implication for Software Development. West Afr. J. Ind. Acad. Res. 2013, 7, 81-92.

11. Ikram, A.; Riaz, H.; Khan, A.S. Eliciting theory of software maintenance outsourcing process: A systematic literature review. Int. J. Comput. Sci. Netw. Secur. 2018, 18, 132-143.

12. Rehman, H.U.; Bamma, H.K.; Nazir, S.; Shahzad, S.; Hodosi, T. A Sourcing Decision Model for Application Maintenance Services. In Proceedings of the 3rd International Conference on Science in Information Technology (ICSITech), Bandung, Indonesia, 25-26 October 2017; pp. 401-407.

13. Holmstrom, H.; Conchúir, E.Ó.; Ågerfalk, P.J.; Fitzgerald, B. Global Software Development Challenges: A Case Study on Temporal, Geographical and Socio-Cultural Distance. In Proceedings of the IEEE International Conference on Global Software Engineering (ICGSE'06), Florianopolis, Brazil, 16-19 October 2006; pp. 3-11.

14. Karami, A.; Guo, Z. A Fuzzy Logic Multi-Criteria Decision Framework for Selecting IT Service Providers. In Proceedings of the 45th Hawaii International Conference on System Sciences, Maui, HI, USA, 4-7 January 2012; pp. 1118-1127.

15. Huang, Y.L.; Sun, W.L. An AHP-based Risk Assessment for an Industrial IoT Cloud. In Proceedings of the International Conference on Software Quality, Reliability and Security Companion (QRS-C), Lisbon, Portugal, 16-20 July 2018 ; pp. 637-638.

16. Chandani, P.; Gupta, C. Requirement Risk Prioritization Using Analytic Hierarchy Process: A Gateway To Identify Risky Requirements. In Proceedings of the 11th International Conference on Contemporary Computing (IC3), Noida, India, 2-4 August 2018; pp. 1-6.

17. Moaven, S.; Habibi, J.; Ahmadi, H.; Kamandi, A. A Decision Support System for Software Architecture-Style Selection. In Proceedings of the 6th International Conference on Software Engineering Research, Management and Applications, Prague, Czech Republic, 20-22 August 2008; pp. 213-220.

18. Büyüközkan, G.; Kahraman, C.; Ruan, D. A Fuzzy Multi-Criteria Decision Approach For Software Development Strategy Selection. Int. J. Gen. Syst. 2004, 33, 259-280. [CrossRef]

19. Silva, V.B.S.; Schramm, F.; Damasceno, A.C. A Multi-Criteria Approach for Selection of Agile Methodologies in Software Development Projects. In Proceedings of the International Conference on Systems, Man, and Cybernetics (SMC), Budapest, Hungary, 9-12 October 2016; pp. 002056-002060.

20. Agrawal, A.; Alenezi, M.; Kumar, R.; Khan, R.A. Measuring The Sustainable-Security Of Web Applications Through A FuzzyBased Integrated Approach Of AHP and TOPSIS. IEEE Access 2019, 7, 153936-153951. [CrossRef]

21. Tanoumand, N.; Ozdemir, D.Y.; Kilic, K.; Ahmed, F. Selecting Cloud Computing Service Provider With Fuzzy AHP. In Proceedings of the International Conference on Fuzzy Systems (FUZZ-IEEE), Naples, Italy, 9-12 July 2017; pp. 1-5.

22. Moaven, S.; Habibi, J. A fuzzy AHP based approach to select software architecture based on quality attributes (FASSA). Knowl. Inf. Syst. 2020, 62, 4569-4597. [CrossRef]

23. Sayed, B.; Shamsi, Z.; Sadiq, M. A Method for the selection of agile methods using AHP. In Proceedings of the 5th International Conference on Frontiers in Intelligent Computing: Theory and Applications, Singapore, 3 March 2017; pp. $297-303$.

24. Ali, S.; Ullah, N.; Abrar, M.F.; Yang, Z.; Huang, J. Fuzzy Multicriteria Decision-Making Approach for Measuring the Possibility of Cloud Adoption for Software Testing. Sci. Program. 2020, 2020, 6597316. [CrossRef]

25. Wang, L.; Ali, Y.; Nazir, S.; Niazi, M. ISA Evaluation Framework for Security of Internet of Health Things System Using AHP-TOPSIS Methods. IEEE Access 2020, 8, 152316-152332. [CrossRef]

26. Li, J.; Ullah, A.; Li, J.; Nazir, S.; Khan, H.U.; Rehman, H.U.; Haq, A.U. Attributes-Based Decision Making for Selection of Requirement Elicitation Techniques Using the Analytic Network Process. Math. Probl. Eng. 2020, 2020, 2156023. [CrossRef] 
27. Alzahrani, F.A. Evaluating the Usable-Security of Healthcare Software Through Unified Technique of Fuzzy Logic, ANP and TOPSIS. IEEE Access 2020, 8, 109905-109916. [CrossRef]

28. Akbar, M.A.; Mahmood, S.; Alsalman, H.; Razzaq, A.; Gumaei, A.; Riaz, M.T. Identification and Prioritization of Cloud Based Global Software Development Best Practices. IEEE Access 2020, 8, 191242-191262. [CrossRef]

29. Ikram, A.; Jalil, M.A.; Ngah1, A.B.; Khan, A.S.; Iqbal, T. Offshore Software Maintenance Outsourcing: Predicting Client's Proposal using Supervised Learning. Int. J. Adv. Trends Comput. Sci. Eng. 2021, 10, 106-113.

30. Akbar, M.A.; Naveed, W.; Mahmood, S.; Alsanad, A.A.; Alsanad, A.; Gumaei, A.; Mateen, A. Prioritization Based Taxonomy of DevOps Challenges Using Fuzzy AHP Analysis. IEEE Access 2020, 8, 202487-202507. [CrossRef]

31. Riskiana, R.R.; Purwandari, B.; Satria, R.; Solichah, I. The Use of Analytic Hierarchy Process to Rank Factors of Software Failures: A Case Study of a Telecommunication Company in Indonesia. In Proceedings of the International Conference on Information Technology Systems and Innovation (ICITSI), Bandung, Indonesia, 23-24 October 2017; pp. 336-341.

32. Nazir, S.; Shahzad, S.; Mahfooz, S.; Nazir, M. Fuzzy logic based decision support system for component security evaluation. Int. Arab J. Inf. Technol. 2018, 15, 224-231.

33. Wang, J.J.; Lin, Z.K.; Huang, H. A decision model for information systems outsourcing: Using a multicriteria method. J. Serv. Sci. Manag. 2008, 1, 1-9. [CrossRef]

34. Faizi, S.; Sałabun, W.; Nawaz, S.; Rehman, A.U.; Wątrobski, J. Best-Worst method and Hamacher aggregation operations for intuitionistic 2-tuple linguistic sets. Expert Syst. Appl. 2021, 181, 115088. [CrossRef]

35. Baczkiewicz, A.; Watróbski, J. Towards MCDA Based Decision Support System Addressing Sustainable Assessment. In Proceedings of the 29th International Conference on Information Systems Development, Valencia, Spain; Universitat Politècnica de València, 2021. Available online: https:/ / aisel.aisnet.org/isd2014/proceedings2021/sustainable/6/ (accessed on 1 September 2021).

36. Shekhovtsov, A.; Więckowski, J.; Kizielewicz, B.; Sałabun, W. Towards Reliable Decision-Making in the green urban transport domain, Facta Univ. Ser. Mech. Eng. 2021. Available online: http://casopisi.junis.ni.ac.rs/index.php/FUMechEng/article/view/ 7407 (accessed on 1 September 2021).

37. Rehman, A.U.; Shekhovtsov, A.; Rehman, N.; Faizi, S.; Sałabun, W. On the Analytic Hierarchy Process Structure in Group Decision-Making Using Incomplete Fuzzy Information with Applications. Symmetry 2021, 13, 609. [CrossRef]

38. Khan, A.W.; Hussain, I.; Zamir, M. Analytic hierarchy process-based prioritization framework for vendor's reliability challenges in global software development. J. Softw. Evol. Process. 2021, 33, e2310. [CrossRef]

39. Hanafizadeh, P.; Ravasan, A.Z. A model for selecting IT outsourcing strategy: The case of e-banking channels. J. Global Inf. Technol. Manag. 2018, 21, 111-138. [CrossRef]

40. Kitchenham, B.; Charters, S. Guidelines for Performing Systematic Literature Reviews in Software Engineering; Keele University: Keele, UK, 2007; EBSE 2007-001.

41. Kitchenham, B. Procedures for Performing Systematic Reviews; Keele University: Keele, UK, 2004; Volume 33, pp. 1-26.

42. Khan, A.A.; Keung, J. Systematic review of success factors and barriers for software process improvement in global software development. IET Softw. 2016, 10, 125-135. [CrossRef]

43. Anwar, R.; Rehman, M.; Wang, K.S.; Hashmani, M.A. Systematic literature review of knowledge sharing barriers and facilitators in global software development organizations using concept maps. IEEE Access 2019, 7, 24231-24247. [CrossRef]

44. Niazi, M.; Ikram, N.; Bano, M.; Imtiaz, S.; Khan, S.U. Establishing trust in offshore software outsourcing relationships: An exploratory study using a systematic literature review. IET Softw. 2013, 7, 283-293. [CrossRef]

45. Salam, M.; Khan, S.U. Challenges in the development of green and sustainable software for software multisourcing vendors: Findings from a systematic literature review and industrial survey. J. Softw. Evol. Process 2018, 30, e1939. [CrossRef]

46. Rashid, N.; Khan, S.U. Agile practices for global software development vendors in the development of green and sustainable software. J. Softw. Evol. Process 2018, 30, e1964. [CrossRef]

47. Ilyas, M.; Khan, S.U. Software integration in global software development: Challenges for GSD vendors. J. Softw. Evol. Process 2017, 29, e1875. [CrossRef]

48. Guo, S.; Zhao, H. Fuzzy best-worst multi-criteria decision-making method and its applications. Knowl.-Based Syst. 2017, 121, 23-31. [CrossRef]

49. Velasquez, M.; Hester, P.T. An analysis of multi-criteria decision making methods. Int. J. Oper. Res. 2013, 10, 56-66.

50. Aires, R.F.; Ferreira, L. The rank reversal problem in multi-criteria decision making: A literature review. Pesqui. Oper. 2018, 38, 331-362. [CrossRef]

51. Kizielewicz, B.; Shekhovtsov, A.; Sałabun, W. A New Approach to Eliminate Rank Reversal in the MCDA Problems. Presented at International Conference on Computational Science, Krakow, Poland, 16-18 June 2021; pp. 338-351.

52. Alazab, F.G.M.; Ayu, M.A. Web Based Multi Criteria Decision Making Using AHP Method. In Proceedings of the 3rd International Conference on Information and Communication Technology for the Moslem World (ICT4M), Jakarta, Indonesia, 13-14 December 2010; pp. A6-A12.

53. Octavianus, R.; Mursanto, P. The analysis of critical success factor ranking for software development and implementation project using AHP. In Proceedings of the International Conference on Advanced Computer Science and Information Systems (ICACSIS), Yogyakarta, Indonesia, 27-28 October 2018; pp. 313-318. 
54. Saaty, T.L. Decision making: The analytic hierarchy and network processes (AHP/ANP). J. Syst. Sci. Syst. Eng. 2004, 13, 1-35. [CrossRef]

55. Akbar, M.A.; Khan, A.A.; Khan, A.W.; Mahmood, S. Requirement change management challenges in GSD: An analytical hierarchy process approach. J. Softw. Evol. Process. 2020, 32, e2246 . [CrossRef]

56. Shameem, M.; Kumar, R.R.; Kumar, C.; Chandra, B.; Khan, A.A. Prioritizing challenges of agile process in distributed software development environment using analytic hierarchy process. J. Softw. Evol. Process. 2018, 30, e1979.

57. Albayrak, E.; Erensal, Y.C. Using analytic hierarchy process (AHP) to improve human performance: An application of multiple criteria decision making problem. J. Intell. Manuf. 2004, 15, 491-503. [CrossRef]

58. Oza, N.V.; Hall, T.; Rainer, A.; Grey, S. Trust in software outsourcing relationships: An empirical investigation of Indian software companies. Inf. Softw. Technol. 2006, 48, 345-354. [CrossRef]

59. Pei, Z.; Xiang, Z.Z.; Ping, H.C. Study on Critical Success Factors for IT Outsourcing Life Cycle. In Proceedings of the International Conference on Wireless and Communications, Networking Mobile Computing, Shanghai, China, 21-25 September 2007; pp. $4379-4382$.

60. Christiansen, H.M. Meeting the Challenge of Communication in Offshore Software Development. In Proceedings of the International Conference on Software Engineering Approaches for Offshore and Outsourced Development, Berlin, Germany, 5 February 2007; pp. 19-26.

61. Riaz, M.R. PMCMG: Project Management Challenges Model for Global Software Development. Ph.D. Thesis, King Fahd University Of Petroleum \& Minerals, Dhahran, Saudi Arabia, 2013.

62. Jain, R.; Suman, U. A project management framework for global software development. ACM SIGSOFT Softw. Eng. Notes 2018, 43, 1-10. [CrossRef]

63. Ali, S.; Hongqi, L.; Khan, S.U.; Zhongguo, Y.; Liping, Z. Success factors for software outsourcing partnership management: An exploratory study using systematic literature review. IEEE Access 2017, 5, 23589-23612. [CrossRef]

64. Britto, R.; Freitas, V.; Mendes, E.; Usman, M. Effort Estimation in Global Software Development: A Systematic Literature Review. In Proceedings of the 9th International Conference on Global Software Engineering, Shanghai, China, 18-21 August 2014; pp. 135-144.

65. Krancher, O.; Dibbern, J. Learning Software Maintenance Tasks in Offshoring Projects: A Cognitive Load Perspective. In Proceedings of the 9th 2012 International Conference of Information Systems, Orlando, FL, USA, 16-19 December 2012; pp. 1-7.

66. Bhatt, P.; Shroff, W.K.G.; Misra, A.K. Influencing factors in outsourced software maintenance. ACM SIGSOFT Softw. Eng. Notes 2006, 31, 1-6. [CrossRef]

67. Kumar, N.; Palvia, P. Global IT outsourcing management: Key influence factors and strategies. J. Inf. Technol. Cases Appl. 2002, 4, 56-75. [CrossRef]

68. Verner, J.M.; Brereton, O.P.; Kitchenham, B.A.; Turner, M.; Niazi, M. Risks and risk mitigation in global software development: A tertiary study. Inf. Softw. Technol. 2014, 56, 54-78. [CrossRef]

69. Davison, R. Offshoring information technology: Sourcing and outsourcing to a global workforce. Inf. Technol. Develop. 2007, 13, 101-102. [CrossRef]

70. Lamersdorf, A.; Munch, J.; Torre, A.F.V.; Sanchez, C.R.; Heinz, M.; Rombach, D. A Rule-Based Model for Customized Risk Identification in Distributed Software Development Projects. In Proceedings of the 5th IEEE International Conference on Global Software Engineering, Princeton, NJ, USA, 23-26 August 2010; pp. 209-218.

71. Vedder, R.; Guynes, C.S.; Reilly, R. Offshoring limitations. Rev. Bus. Inf. Syst. 2010, 14. Available online: https://clutejournals. com/index.php/RBIS/article/view/501 (accessed on 1 September 2021). [CrossRef]

72. Islam, S.; Joarder, M.M.A.; Houmb, S.H. Goal and Risk Factors in Offshore Outsourced Software Development from Vendor's Viewpoint. In Proceedings of the 2009 Fourth IEEE International Conference on Global Software Engineering, Limerick, Ireland, 13-16 July 2009; pp. 347-352.

73. Beulen, E.; Fenema, P.V.; Currie, W. From application outsourcing to infrastructure management: Extending the offshore outsourcing service portfolio. Eur. Manag. J. 2005, 23, 133-144. [CrossRef]

74. Abdullah, L.M.; Verner, J.M. Analysis and application of an outsourcing risk framework. J. Syst. Softw. 2012, 85, 1930-1952. [CrossRef]

75. Sneed, H.M. Offering Software Maintenance as an Offshore Service. In Proceedings of the 2008 IEEE International Conference on Software Maintenance, Beijing, China, 28 September-4 October 2008 ; pp. 1-5.

76. Britto, R. Knowledge Classification for Supporting Effort Estimation in Global Software Engineering Projects. Ph.D. Dissertation, Department of Software Engineering, Blekinge Institute of Technology, Karlshamn, Sweden, 2015.

77. Winkler, J.K.; Dibbern, J.; Heinzl, A. The impact of cultural differences in offshore outsourcing-Case study results from German-Indian application development projects. Inf. Syst. Front. 2008, 10, 243-258. [CrossRef]

78. Bajta, M.E.; Idri, A.; Ros, J.N.; Alemán, J.L.F.; Gea, J.M.C.D.; García, F.; Toval, A. Software project management approaches for global software development: A systematic mapping study. Tsinghua Sci. Technol. 2018, 23, 690-714. [CrossRef]

79. Nazir, S.; Shahzad, S.; Abid, S.B.S. Selecting software design based on birthmark. Life Sci. J. 2014, 11, 89-93. 
80. Palcic, I.; Lalic, B. Analytical Hierarchy Process as a tool for selecting and evaluating projects. Int. J. Simul. Model. 2009, 8, 16-26. [CrossRef]

81. Sehra, S.K.; Brar, Y.S.; Kaur, N. Multi criteria decision making approach for selecting effort estimation model. Int. J. Comput. Appl. 2013, 39, 0975-8887. 